\begin{tabular}{|c|l|}
\hline Title & Partial Harmonization of Corporate Taxes in an A symmetric Repeated Game Setting \\
\hline Author(s) & Itaya, Jun-ichi; Okamura, Makoto; Y amaguchi, Chikara \\
\hline Citation & Discussion Paper, Series A, 229, 1-35 \\
\hline Issue Date & 2010-11 \\
\hline Doc URL & http:/hdl.handle.net/2115/44188 \\
\hline Type & bulletin (article) \\
\hline File Information & DPA229_new.pdf \\
\hline
\end{tabular}

Instructions for use 
Discussion Paper, Series A, No. 2010-229

\section{Partial Harmonization of Corporate Taxes in an Asymmetric Repeated Game Setting \\ Jun-ichi Itaya, \\ Makoto Okamura, \\ Chikara Yamaguchi}

November 1, 2010

Graduate School of Economics \& Business Administration

Hokkaido University

Kita 9 Nishi 7, Kita-Ku, Sapporo 060-0809, JAPAN 


\title{
Partial Harmonization of Corporate Taxes in an Asymmetric Repeated Game Setting*
}

\author{
Jun-ichi Itaya ${ }^{\dagger}$ Makoto Okamura $\stackrel{\ddagger}{\ddagger}$ Chikara Yamaguchi ${ }^{\S}$
}

November 1, 2010

\begin{abstract}
This paper investigates the conditions under which partial harmonization for capital taxation is sustained in a repeated interactions model of tax competition when there are three heterogenous countries with respect to their capital endowments. We show that regardless of the structure of the coalition (i.e., any group of countries), whether partial tax harmonization is sustainable or not crucially depends on the capital endowment of the median country relative to those of the large and small countries. The most noteworthy finding is that the closer the capital endowment of the median country to the average capital endowment of the large and small countries, the less likely is the tax harmonization including the median country to prevail and the more likely is the partial tax harmonization excluding the median country to prevail.
\end{abstract}

JEL classification: H73; F59; F21

Keywords: Tax coordination; Asymmetric countries; Repeated game; Tax competition

\footnotetext{
${ }^{*}$ We thank Keisuke Kawachi for the many helpful comments. The first (Itaya), second (Okamura), and third (Yamaguchi) authors gratefully acknowledge the financial support provided by the Grant-in-Aid for Scientific Research from the Japan Society for the Promotion of Science (\#2153029), (\#20330052), and (\#20730226), respectively.

${ }^{\dagger}$ Corresponding author. Graduate School of Economics and Business Administration, Hokkaido University, Sapporo 060-0809, Japan. Tel: +81-11-706-2858; Fax: +81-11-706-4947; E-mail: itaya@econ.hokudai.ac.jp

${ }_{\ddagger}^{\ddagger}$ Economics Department, Hiroshima University, 1-2-1 Kagamiyama, Higashihiroshima, Hiroshima 739-8526, Japan. Tel: +81-82-424-7275; E-mail: okamuram@hiroshima-u.ac.jp

${ }^{\S}$ Faculty of Economic Sciences, Hiroshima Shudo University, 1-1-1 Ozukahigashi, Asaminami-ku, Hiroshima 7313195, Japan. Tel: +81-82-830-1238; Fax: +81-82-830-1313; E-mail: chikara@shudo-u.ac.jp
} 


\section{Introduction}

Although in the European Union (EU), the tax harmonization of corporate taxation has been debated since the European Economic Community was established, the EU has never been successful in implementing any serious cooperation or harmonization in corporate taxation. This would make partial tax harmonization a more attractive and realistic policy option for politicians and economists in order to overcome the inefficiency in world capital allocation resulting from non-harmonized capital taxation based on the source principle. Since only a subset of countries need to agree on the harmonized policy in the case of partial tax harmonization, the political constraints are less stringent. Indeed, subsets of EU members (with a minimum of 8 countries) have been recently institutionalized under the name of "Enhanced Cooperation Agreements (ECA)" by the treaties of Amsterdam (1997) and Nice (2003). An ECA can be activated only when not all 27 member countries agree to coordinate their policies on a particular issue such as harmonizing corporate tax policy.

The academic concern has been fuelled by the increasing public debate on partial harmonization in such forms as ECA, which has resulted in several papers in the theoretical literature on partial tax coordination. Burbidge et al. (1997) analyze the endogenous coalition formation for jurisdictional capital tax policy in a standard model of capital tax competition, and demonstrate that the grand coalition among all jurisdictions is realized as a unique equilibrium even in a static setting if the number of jurisdictions is only two, but this is not the case if there exist three or more jurisdictions. Konrad and Schjelderup (1999) demonstrate that in the standard tax competition framework with identical countries, based on the assumption of strategic complementarity between the tax rates of a partial tax union and outside countries, partial harmonization can improve not only the welfare of the union but also that of the outside countries. Rasmussen (2001) applies a numerical analysis to a linear-quadratic tax competition model with imperfect capital mobility and an arbitrary number of identical countries and points out that a very large percentage of the economies of the is needed to take part in capital income tax coordination to reap a significant gain, with the main benefits accruing to the outside countries. Kachelein (2004) considers partial harmonization in a model with a large number of symmetric countries, and finds that a welfare loss arises for the partial union that implements tax harmonization when it is small relative to the world capital market, while all countries gain from partial harmonization when the union is very large relative to the capital market. More recently, Sugahara et al. (2009) extend Konrad and Schjelderup's model by introducing two types of countries that differ only in population, and show that partial harmonization, regardless of 
whether each coalition consists of only small countries or only large counties, improves the welfare of all countries. Using a model with an arbitrary number of countries that differ in population, Bucovetsky (2009) shows that any partial tax harmonization not only increases the average payoff of the member jurisdictions in the tax union but also benefits the residents of all jurisdictions not in the tax union and the largest jurisdiction in the tax union. Using an asymmetric three-country model whose countries differ in size, Vrijburg (2009) shows that partial harmonization induces inside countries to increase their tax rates but outside countries to either increase or decrease their tax rates, while it unambiguously augments the welfare levels of the outside countries.

Although such tax coordination (harmonization) among all jurisdictions would be desirable or Pareto-improving compared to a Nash equilibrium in a one-shot tax competition game, it is generally difficult to realize it in reality owing to decentralized decision making. This is because every jurisdiction usually has an incentive to deviate from the coordination that maintains higher harmonized tax rates in order to reap short-run gains. In contrast, using repeated interactions models, Cardarelli et al. (2002), Catenaro and Vidal (2006), and Itaya et al. (2008) show that based on Folk Theorem arguments, full tax harmonization can emerge as an self-enforced equilibrium among decentralized jurisdictions as long as sovereign jurisdictions are sufficiently patient. Although their dynamic settings have provided an implicit coordination mechanism to sustain tax coordination among jurisdictions, all of them have focused on the sustainability of full tax coordination. Unfortunately, partial tax harmonization is out of the scope of their analyses.

This paper makes a contribution to the understanding of partial tax harmonization in a repeated interactions model of tax competition. In particular, we investigate the conditions under which partial capital tax harmonization among heterogenous or asymmetric countries in terms of capital endowments is sustained as an equilibrium outcome. To do this, we employ a three-country model that is rich enough to capture some of the central features of tax competition between asymmetric countries but simple enough to yield sharp insights into some of the central questions such as the sustainability of partial tax harmonization supported by a tax union consisting of any subset of countries. As emphasized by Peralta and van Ypersele (2006), Bucovetsky (2009), and Vrijburg (2009), even in the conventional static tax competition game, the asymmetries between the countries greatly influence the sustainability of partial tax coordination. When the countries are asymmetric, some countries might be actually worse off from tax harmonization compared to tax competition, since a given country's characteristics decide whether it will be a loser or winner from tax harmonization. Such inter-jurisdictional conflict would, therefore, lead to the failure of full harmonization. Even 
in a repeated interactions model consisting of two asymmetric countries, Cardarelli et al. (2002) and Catenaro and Vidal (2006) show that if the difference in capital endowments, preferences of inhabitants, and/or, production technologies are sufficiently large, full tax harmonization between the two countries is not sustainable.

We show that tax harmonization supported by either all countries or any subset of heterogenous countries (i.e., full harmonization and three types of partial harmonization between two countries) can be sustained as a subgame perfect equilibrium of the repeated game if the member countries included in the union are sufficiently patient. The most noteworthy finding is that a medium-sized country in terms of capital endowment always plays a crucial role in the successful implementation for tax harmonization among heterogenous countries. To be more specific, the closer the capital endowment of the median country to the average capital endowment of the large and small countries, the less likely is the tax harmonization including the median country to prevail, and the more likely is the partial tax harmonization excluding the median country to prevail.

The rest of the paper is organized as follows. Section 2 presents the structure of the one-shot tax competition game and characterizes its fully noncooperative Nash equilibrium. Section 3 constructs a repeated interactions model of full tax harmonization wherein all countries cooperate with regard to their tax policies and investigates the likelihood of the coordination. Section 4 investigates the sustainability of partial tax harmonization among a subset of countries. Section 5 compares the welfare levels across countries in tax competition and under various types of partial tax harmonization. Section 6 concludes the paper with several remarks and a discussion of the extensions.

\section{The Model}

Consider an economy composed of three countries which are heterogenous with respect to capital endowments. The per capita capital endowments of the large, medium, and small countries, are respectively, represented as $\bar{k}_{i}, i=L, M, S$. Without loss of generality, we assume that $\bar{k}_{L} \geq \bar{k}_{M} \geq$ $\bar{k}_{S}$; moreover, for the later comparative statics analysis, it is convenient to rewrite them as follows: $\bar{k}_{L}=\bar{k}_{A}+\varepsilon, \bar{k}_{M}=\bar{k}_{A}+\varepsilon \theta$ and $\bar{k}_{S}=\bar{k}_{A}-\varepsilon$, where $\bar{k}_{A} \equiv\left(\bar{k}_{L}+\bar{k}_{S}\right) / 2$ represents the average capital endowment of countries $L$ and $S, \varepsilon>0$ is the difference in the capital endowments of $\bar{k}_{A}$ and $\bar{k}_{L}$ (or $\bar{k}_{S}$ ), and $\theta \in[-1,1]$ is the ratio of $\bar{k}_{M}-\bar{k}_{A}$ relative to $\bar{k}_{L}-\bar{k}_{A}\left(\right.$ or $\left.\bar{k}_{A}-\bar{k}_{S}\right)$. In particular, when $\theta=1(\theta=-1)$, the capital endowment of country $M$ coincides with that of country $L$ (country $S$ ), while when $\theta=0$, the capital endowment of country $M$ is precisely equal to $\bar{k}_{A}$. Using these 


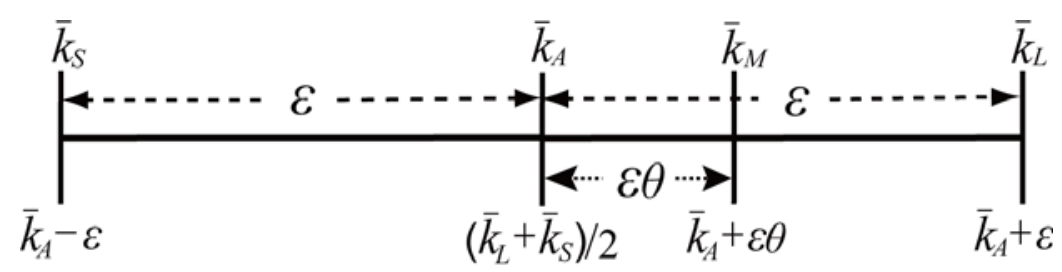

Figure 1: Distribution of the capital endowments of the three coutries when $\theta \in[0,1]$.

notations, the distribution of the capital endowments of the three countries are illustrated in Fig.1.

In each country, there exist a representative household and a representative firm; workers are immobile across countries while capital is perfectly mobile. These factors are used in the production of a numéraire good. Following Bucovetsky (1991, 2009), Peralta and van Ypersele (2006), and Itaya et al. (2008), we assume the constant-returns-to-scale production function in an intensive form: $f\left(k_{i}\right) \equiv\left(a-k_{i}\right) k_{i}$, where $a>0$ stands for a technology parameter that is assumed to be identical across all countries and $k_{i}$ is the per capita amount of capital demanded in country $i$. We further assume that $a>2 k_{i}$ to ensure positive but diminishing marginal productivity of capital. Public expenditures, $g_{i}$, are entirely financed by a source-based tax on capital $\tau_{i}$, so that the budget constraint of the government of country $i$ is expressed as $g_{i}=\tau_{i} k_{i}$. Given the market prices and the tax rates, the profit-maximizing input choices are characterized by the following first-order conditions: $r=f^{\prime}\left(k_{i}\right)-\tau_{i}=a-2 k_{i}-\tau_{i}$ and $w_{i}=f\left(k_{i}\right)-k_{i} f^{\prime}\left(k_{i}\right)=k_{i}^{2}$, where $r$ is the net return on capital and $w_{i}$ is the country-specific wage rate. ${ }^{1}$ The international mobility of capital ensures that the net return on capital is equalized across all countries. Hence, the capital market equilibrium is characterized by this arbitrage condition for all $i$ and the capital market clearing condition $\sum k_{i}=\bar{k}_{L}+\bar{k}_{M}+\bar{k}_{S}=$ $3 \bar{k}_{A}+\varepsilon \theta$. In equilibrium, the net return on capital and the amount of capital demanded in country $i$, respectively, are as follows:

$$
\begin{aligned}
& r^{*}=a-2 \bar{k}_{A}-\frac{2}{3} \varepsilon \theta-\bar{\tau} \\
& k_{i}^{*}=\bar{k}_{A}+\frac{1}{3} \varepsilon \theta+\frac{1}{2}\left(\bar{\tau}-\tau_{i}\right), \quad i=L, M, S,
\end{aligned}
$$

where $\bar{\tau} \equiv\left(\tau_{L}+\tau_{M}+\tau_{S}\right) / 3$ is the average capital tax rate of all three countries. Differentiating (1) and (2) with respect to $\tau_{i}$ yields the following impacts:

$$
\frac{\partial r^{*}}{\partial \tau_{i}}=-\frac{1}{3}<0, \frac{\partial k_{i}^{*}}{\partial \tau_{i}}=-\frac{1}{3}<0 \text { and } \frac{\partial k_{j}^{*}}{\partial \tau_{i}}=\frac{1}{6}>0, \quad i \neq j .
$$

\footnotetext{
${ }^{1} \mathrm{~A}$ non-negative constraint on $r$ implies that $a-2 k_{i} \geq \tau_{i}$.
} 
An increase in $\tau_{i}$ reduces the net remuneration on capital in country $i$, leading to an outflow of capital. A fall in $r$ is caused both by the direct reduction in the net remuneration on capital in country $i$ and by the decrease in the marginal productivity of capital in other countries due to the inflow of capital.

The representative residents of all countries are identical. They inelastically supply one unit of labor to the domestic firms and invest their own capital holdings in the home and foreign countries. They also spend their income on the consumption of the numéraire good $c_{i}$. Accordingly, the budget constraint of a household in country $i$ is expressed as $c_{i}=w_{i}+r \bar{k}_{i}$. Taking (1), (2), and the tax rates chosen by the other countries as given, the government of country $i$ chooses $\tau_{i}$ so as to maximize the utility function of its resident: $u_{i}\left(c_{i}, g_{i}\right) \equiv c_{i}+g_{i}=f\left(k_{i}^{*}\right)+r^{*}\left(\bar{k}_{i}-k_{i}^{*}\right)$. Together with a quadratic production function, the assumed specification of linear utility allows us to derive a closedform solution for the equilibrium tax rates associated with the different phases of the repeated tax competition game defined later (see also Bucovetsky, 1991, 2009; Peralta and van Ypersele, 2006). The first-order condition for country $i$ is as follows:

$$
\frac{\partial u_{i}}{\partial \tau_{i}}=\left[f^{\prime}\left(k_{i}^{*}\right)-r^{*}\right] \frac{\partial k_{i}^{*}}{\partial \tau_{i}}+\left(\bar{k}_{i}-k_{i}^{*}\right) \frac{\partial r^{*}}{\partial \tau_{i}}=0
$$

Substituting (3) into (4) and rearranging yields the best-response function of country $i$ :

$$
\tau_{i}=\frac{1}{8}\left[\tau_{j}+\tau_{h}+2 \varepsilon \theta+6\left(\bar{k}_{A}-\bar{k}_{i}\right)\right], i \neq j \neq h,
$$

which reveals that the tax rates of different countries are strategic complements (see Konrad and Schjelderup, 1999). By solving the best-response function (5) for all countries simultaneously, we can obtain the following Nash equilibrium tax rates, denoted by $\tau_{i}^{N}$, in the one-shot tax competition game:

$$
\tau_{L}^{N}=-\frac{2}{9} \varepsilon(3-\theta)<0, \quad \tau_{M}^{N}=-\frac{4}{9} \varepsilon \theta \gtreqless 0, \text { and } \tau_{S}^{N}=\frac{2}{9} \varepsilon(3+\theta)>0 .
$$

Substituting (6) into (1) and (2) and recalling that $\bar{\tau}=0$ in the Nash equilibrium yields the following Nash equilibrium net return and the amount of capital demand in country $i$, respectively:

$$
\begin{aligned}
r^{N} & =a-2 \bar{k}_{A}-\frac{2}{3} \varepsilon \theta, \\
k_{L}^{N} & =\bar{k}_{A}+\frac{1}{9} \varepsilon(3+2 \theta), \quad k_{M}^{N}=\bar{k}_{A}+\frac{5}{9} \varepsilon \theta, \text { and } k_{S}^{N}=\bar{k}_{A}-\frac{1}{9} \varepsilon(3-2 \theta) .
\end{aligned}
$$


It follows from (8) that $\bar{k}_{L}-k_{L}^{N}=2 \varepsilon(3-\theta) / 9>0, \bar{k}_{S}-k_{S}^{N}=-2 \varepsilon(3+\theta) / 9<0$, and $\bar{k}_{M}-k_{M}^{N}=$ $4 \varepsilon \theta / 9 \gtreqless 0$; in words, country $L$ exports capital with subsidy (i.e., $\tau_{L}^{N}<0$ ), while country $S$ imports capital with taxation (i.e., $\tau_{S}^{N}>0$ ). This result is caused by the well-known terms of trade effect; i.e., capital importers (exporters) are willing to levy positive (negative) tax rates on capital in order to decrease (increase) the capital payments through a reduction (rise) in the price of capital, $r^{*}$, in (1) (note that the Nash equilibrium price of capital, $r^{N}$, in (7) is independent of the tax rates). Although the net exporting positions of countries $L$ and $S, \bar{k}_{i}-k_{i}^{N}, i=L, S$, remain unchanged regardless of the changes in $\theta$, country $M$ may become a capital importer or exporter depending solely on $\theta$; more specifically, country $M$ may be either an importer with taxation (i.e., $\tau_{M}^{N}>0$ ) for $\theta \in[-1,0)$ or an exporter with subsidy (i.e., $\left.\tau_{M}^{N}<0\right)$ for $\theta \in(0,1]$. Notably, when $\theta=0$, country $M \operatorname{sets} \tau_{M}^{N}=0$, because its net trade of capital is equal to zero (i.e., $k_{M}^{N}=\bar{k}_{M}$ ), and thus country $M$ neither gains nor looses by manipulating $\tau_{M}^{N}$.

By making use of (7) and (8), we obtain the utility levels of the three countries at the Nash equilibrium:

$$
\begin{aligned}
u_{L}^{N} & =\left(a-\bar{k}_{A}\right) \bar{k}_{A}+\left(a-2 \bar{k}_{A}\right) \varepsilon+\frac{1}{81} \varepsilon^{2}\left(8 \theta^{2}-48 \theta-9\right), \\
u_{M}^{N} & =\left(a-\bar{k}_{A}\right) \bar{k}_{A}+\left(a-2 \bar{k}_{A}\right) \varepsilon \theta-\frac{49}{81} \varepsilon^{2} \theta^{2}, \\
u_{S}^{N} & =\left(a-\bar{k}_{A}\right) \bar{k}_{A}-\left(a-2 \bar{k}_{A}\right) \varepsilon+\frac{1}{81} \varepsilon^{2}\left(8 \theta^{2}+48 \theta-9\right),
\end{aligned}
$$

which, upon subtraction yield:

$$
\begin{aligned}
& u_{L}^{N}-u_{M}^{N}=\varepsilon(1-\theta)\left[r^{N}-\frac{1}{27} \varepsilon(3+\theta)\right] \geq 0, \\
& u_{M}^{N}-u_{S}^{N}=\varepsilon(1+\theta)\left[r^{N}+\frac{1}{27} \varepsilon(3-\theta)\right] \geq 0,
\end{aligned}
$$

whose nonnegative signs can be confirmed by using the value of $r^{N}$ as given in (7). ${ }^{2}$ These welfare comparisons reveal that the welfare level of a capital-rich country is always higher than that of a capital-poor country in the noncooperating (Nash) equilibrium; i.e., $u_{L}^{N} \geq u_{M}^{N} \geq u_{S}^{N}$.

\footnotetext{
${ }^{2}$ The nonnegative sign of $u_{L}^{N}-u_{M}^{N}$ can be demonstrated using the assumption of diminishing marginal productivity of capital, i.e., $k_{L}^{N}<a / 2$, considering the nonnegative interest rate $r^{N}-2 \varepsilon(3-\theta) / 9 \geq 0$, and exploiting the fact that $r^{N}-[\varepsilon(3+\theta) / 27] \geq r^{N}-[2 \varepsilon(3-\theta) / 9] \geq 0$.
} 


\section{Full Harmonization}

In this section, we construct a simple repeated tax competition game where all countries posses a common discount factor $\delta \in[0,1)$. We use the terms "coalition" and "union" to refer to any group of countries that agree to implement tax harmonization. Let $G$ represent a subset of countries; i.e., $G \subseteq\{L, M, S\}$. For simplicity, we consider all possible coalitions, except for a coalition with a single country, and hence $G \in\{\{L, M\},\{L, S\},\{M, S\},\{L, M, S\}\}$. For notational simplicity, we denote, for example, the set $\{L, M\}$ simply as $L M$.

Given these notations, we use shorthand for the utility function of country $i$ as follows:

$$
\begin{aligned}
u_{i}^{j}(G) & \equiv u_{i}^{j}\left(c_{i}^{j}(G), g_{i}^{j}(G)\right)=c_{i}^{j}(G)+g_{i}^{j}(G) \\
& =f\left(k_{i}^{j}(G)\right)+r_{i}^{j}(G)\left[\bar{k}_{i}-k_{i}^{j}(G)\right], j=C, D
\end{aligned}
$$

where we index all the endogenous variables pertaining to a tax union by $G$ as $c_{i}^{j}(G), g_{i}^{j}(G), r_{i}^{j}(G)$, and $k_{i}^{j}(G)$ for $j=C, D$ that will be defined later.

Assume that in every period, each country belonging to union $G$ sets a common capital tax rate on condition that the other countries belonging to union $G$ follow it in the previous period. If at least one country deviates from it, then their cooperation collapses, thus triggering the punishment phase that results in the Nash equilibrium, which persists forever. To sustain cooperation, the following condition for country $i$ belonging to union $G$ must be satisfied:

$$
\frac{1}{1-\delta} u_{i}^{C}(G) \geq u_{i}^{D}(G)+\frac{\delta}{1-\delta} u_{i}^{N}, \quad i \in G
$$

The left-hand side of (12) is the discounted total utility for a representative resident in country $i$ when the tax harmonization supported by union $G$ is infinitely sustained, while its right-hand side represents the sum of the utility resulting from the deviation by setting the best-deviation tax rate in the current period and the total discounted utility resulting from the Nash phase in all following periods.

Consider first the full harmonization supported by the ground coalition $G=L M S$ wherein all three countries agree to jointly set their capital tax rates. Namely, maximizing the utilitarian social welfare function $W(L M S) \equiv u_{L}+u_{M}+u_{S}=f\left(k_{L}^{*}\right)+f\left(k_{M}^{*}\right)+f\left(k_{S}^{*}\right)$ with respect to $\tau_{i}, i=L, M, S$, 
yields the following first-order conditions: ${ }^{3}$

$$
\frac{\partial W(L M S)}{\partial \tau_{i}}=f^{\prime}\left(k_{L}^{*}\right) \frac{\partial k_{L}^{*}}{\partial \tau_{i}}+f^{\prime}\left(k_{M}^{*}\right) \frac{\partial k_{M}^{*}}{\partial \tau_{i}}+f^{\prime}\left(k_{S}^{*}\right) \frac{\partial k_{S}^{*}}{\partial \tau_{i}}=0, \quad i=L, M, S .
$$

Solving these functions using (2) and (3) yields the harmonized common tax rate $\tau^{C}$, i.e., $\tau_{L}=$ $\tau_{M}=\tau_{S} \equiv \tau^{C}$, although its level is indeterminate (see also Peralta and van Ypersele, 2006; Itaya et al., 2008). The common tax rate $\tau^{C}$ is due to the identical production and utility functions. The first best (i.e., the equalization of the marginal productivity of capital in all countries) can be achieved by any tax level as long as all countries set the same tax rate. For simplicity, in the case of full harmonization, we drop the notation $G$ from the endogenous variable pertaining to union $G$. Substituting this result into (1) and (2) yields the net return, $r^{C}$, and the domestic demand for capital, $k_{i}^{C}, i=L, M, S$, respectively:

$$
\begin{aligned}
& r^{C}=a-2 \bar{k}_{A}-\frac{2}{3} \varepsilon \theta-\tau^{C}=r^{N}-\tau^{C}, \\
& k_{L}^{C}=k_{M}^{C}=k_{S}^{C}=\bar{k}_{A}+\frac{1}{3} \varepsilon \theta .
\end{aligned}
$$

It follows from (14) that when full tax harmonization is implemented, country $L$ becomes a capital exporter and country $S$ becomes a capital importer, i.e., $\bar{k}_{L}-k_{L}^{C}=\varepsilon[1-(1 / 3) \theta]>0$ and $\bar{k}_{S}-k_{S}^{C}=$ $-\varepsilon[1+(1 / 3) \theta]<0$, while the net exporting position of country $M, \bar{k}_{M}-k_{M}^{C}=2 \varepsilon \theta / 3$, relies on $\theta$; i.e., country $M$ is a capital importer when $\theta \in[-1,0)$, an exporter when $\theta \in(0,1]$, and its net trade of capital is equal to zero at $\theta=0$.

The resulting utility levels of the respective countries when full harmonization is implemented, $u_{i}^{C}$, are as follows:

$$
\begin{aligned}
u_{L}^{C} & =\left(a-\bar{k}_{A}\right) \bar{k}_{A}+\left(a-2 \bar{k}_{A}\right) \varepsilon-\frac{1}{9} \varepsilon\left[3 \tau^{C}(3-\theta)+\varepsilon \theta(6-\theta)\right] \\
u_{M}^{C} & =\left(a-\bar{k}_{A}\right) \bar{k}_{A}+\left(a-2 \bar{k}_{A}\right) \varepsilon \theta-\frac{1}{9} \varepsilon \theta\left(6 \tau^{C}+5 \varepsilon \theta\right), \\
u_{S}^{C} & =\left(a-\bar{k}_{A}\right) \bar{k}_{A}-\left(a-2 \bar{k}_{A}\right) \varepsilon+\frac{1}{9} \varepsilon\left[3 \tau^{C}(3+\theta)+\varepsilon \theta(6+\theta)\right] .
\end{aligned}
$$

Although full harmonization results in an indeterminate capital tax rate, the participation constraints for the respective countries, i.e., $u_{i}^{C} \geq u_{i}^{N}$ for $i=L, M, S$, reduce the possible range of harmonized

\footnotetext{
${ }^{3}$ More generally, the social welfare function can be expressed as $W \equiv N_{L} u_{L}+N_{M} u_{M}+N_{S} u_{S}$, which is weighted by the population of each country, $N_{i}$. However, the assumption of identical population allows us to eliminate $N_{i}$, $i=L, M, S$.
} 
tax rates as follows:

$$
\begin{aligned}
& \tau^{C} \in\left[-\frac{1}{27} \varepsilon(3+\theta), \frac{2}{27} \varepsilon \theta\right] \text { if } \theta \in[0,1], \\
& \tau^{C} \in\left[\frac{2}{27} \varepsilon \theta, \frac{1}{27} \varepsilon(3-\theta)\right] \text { if } \theta \in[-1,0] .
\end{aligned}
$$

As seen from (18), given a constant $\varepsilon>0$, the closer the capital endowment of country $M$ to that of country $L$ or country $S$ (i.e., $\theta \rightarrow \pm 1$ ), the wider the tax range (18), as illustrated in Figs.2 -5 . On the other hand, given a constant $\theta \neq 0$, the larger the difference in the capital endowments of countries $L$ and $S$ (measured by $2 \varepsilon$ ), the wider the tax range (18).

To identify the conditions under which the full harmonization that satisfies the tax range (18) is sustained, we first need to calculate the best-deviation tax rate of country $i$, denoted by $\tau_{i}^{D}$, that maximizes $u_{i}$ given that all other countries except for $i$ follow the harmonized tax rate $\tau^{C}$. Setting $\tau_{j}=\tau_{h}=\tau^{C}$ in (5) yields the best-deviation tax rates chosen by the respective countries:

$$
\begin{aligned}
\tau_{L}^{D} & =\frac{1}{4}\left[\tau^{C}-\varepsilon(3-\theta)\right], \\
\tau_{M}^{D} & =\frac{1}{4}\left[\tau^{C}-2 \varepsilon \theta\right], \\
\tau_{S}^{D} & =\frac{1}{4}\left[\tau^{C}+\varepsilon(3+\theta)\right] .
\end{aligned}
$$

When country $L$ deviates from $\tau^{C}$ by choosing $\tau_{L}^{D}$, while countries $M$ and $S$ follow $\tau^{C}$, the net return on capital, the capital demand in country $L$, and its utility level are, respectively, obtained from (1), (2), and (19), and recalling that $\tau_{M}=\tau_{S}=\tau^{C}$ as follows:

$$
\begin{aligned}
r_{L}^{D} & =a-2 \bar{k}_{A}+\frac{1}{4} \varepsilon(1-3 \theta)-\frac{3}{4} \tau^{C} \\
k_{L}^{D} & =\bar{k}_{A}+\frac{1}{4}\left[\varepsilon(1+\theta)+\tau^{C}\right] \\
u_{L}^{D} & =\left(a-\bar{k}_{A}\right) \bar{k}_{A}+\left(a-2 \bar{k}_{A}\right) \varepsilon+\frac{1}{8}\left[\left(\tau^{C}\right)^{2}-2 \varepsilon(3-\theta) \tau^{C}+\varepsilon^{2}\left(\theta^{2}-6 \theta+1\right)\right] .
\end{aligned}
$$

Similarly, when country $M$ deviates from $\tau^{C}$ by choosing $\tau_{M}^{D}$, while countries $L$ and $S$ follow $\tau^{C}$, we have

$$
\begin{aligned}
r_{M}^{D} & =a-2 \bar{k}_{A}-\frac{1}{2} \varepsilon \theta-\frac{3}{4} \tau^{C} \\
k_{M}^{D} & =\bar{k}_{A}+\frac{1}{2} \varepsilon \theta+\frac{1}{4} \tau^{C} \\
u_{M}^{D} & =\left(a-\bar{k}_{A}\right) \bar{k}_{A}+\left(a-2 \bar{k}_{A}\right) \varepsilon \theta+\frac{1}{8}\left[\left(\tau^{C}\right)^{2}-4 \varepsilon \theta \tau^{C}-4 \varepsilon^{2} \theta^{2}\right] .
\end{aligned}
$$


Finally, when country $S$ deviates from $\tau^{C}$ by choosing $\tau_{S}^{D}$, while countries $L$ and $S$ follow $\tau^{C}$, we obtain

$$
\begin{aligned}
r_{S}^{D} & =a-2 \bar{k}_{A}-\frac{1}{4} \varepsilon(1+3 \theta)-\frac{3}{4} \tau^{C} \\
k_{S}^{D} & =\bar{k}_{A}-\frac{1}{4}\left[\varepsilon(1-\theta)-\tau^{C}\right] \\
u_{S}^{D} & =\left(a-\bar{k}_{A}\right) \bar{k}_{A}-\left(a-2 \bar{k}_{A}\right) \varepsilon+\frac{1}{8}\left[\left(\tau^{C}\right)^{2}+2 \varepsilon(3+\theta) \tau^{C}+\varepsilon^{2}\left(\theta^{2}+6 \theta+1\right)\right] .
\end{aligned}
$$

By rearranging (12), we can explicitly derive the minimum discount factors of the three countries:

$$
\underline{\delta}_{i} \equiv \frac{u_{i}^{D}-u_{i}^{C}}{u_{i}^{D}-u_{i}^{N}}, \quad i=L, M, S .
$$

Only when the actual (common) discount factor of all three countries, $\delta$, is greater than the threshold value of the discount factor defined by $\delta^{*} \equiv \max \left[\underline{\delta}_{L}, \underline{\delta}_{M}, \underline{\delta}_{S}\right]$, the harmonized tax rate $\tau^{C}$ can be sustained as a subgame perfect Nash equilibrium of the repeated game. Substituting (9), (10), (11), (15), (16), (17), (22), (23), and (24) into (25) and rearranging yields the minimum discount factors of the respective countries above which they find it to be in their interest to cooperate as follows:

$$
\begin{aligned}
\underline{\delta}_{L} & =\frac{9\left[3 \tau^{C}+\varepsilon(3-\theta)\right]^{2}}{\left[9 \tau^{C}-\varepsilon(3-\theta)\right]\left[9 \tau^{C}-17 \varepsilon(3-\theta)\right]}, \\
\underline{\delta}_{M} & =\frac{9\left(3 \tau^{C}+2 \varepsilon \theta\right)^{2}}{\left(9 \tau^{C}-2 \varepsilon \theta\right)\left(9 \tau^{C}-34 \varepsilon \theta\right)}, \\
\underline{\delta}_{S} & =\frac{9\left[3 \tau^{C}-\varepsilon(3+\theta)\right]^{2}}{\left[9 \tau^{C}+\varepsilon(3+\theta)\right]\left[9 \tau^{C}+17 \varepsilon(3+\theta)\right]} .
\end{aligned}
$$

Although any harmonized common tax rate $\tau^{C}$ satisfying the range (18) can realize the first-best allocation of capital by eliminating the tax differentials across countries, each country's incentive to cooperate is critically influenced by the chosen level of harmonized tax rate $\tau^{C}$. Indeed, it can be easily verified that $\underline{\delta}_{L}$ in (26) is increasing in $\tau^{C}$ and $\underline{\delta}_{S}$ in (28) is decreasing in $\tau^{C}$, while the locus of $\underline{\delta}_{M}$ in (27) crucially hinges on the capital endowment of country $M$ relative to those of countries $L$ and $S$ (i.e., $\theta$ ); to be more precise, $\underline{\delta}_{M}$ is increasing (decreasing) in $\tau^{C}$ if $\theta>3 / 17(\theta<-3 / 17$ ), while it is not monotonic in $\tau^{C}$ if $\theta \in[-3 / 17,3 / 17]$ (see the appendix of the paper). Figs.2, 3, 4, and 5 depict the behavior of the minimum discount factors of all three countries with respect to $\tau^{C}$ for $\theta=1,1 / 3,-1 / 3$, and -1 , respectively. It follows from the definition of $\delta^{*},(18),(26),(27)$, and (28) (see the appendix) that the threshold values of the discount factors associated with different values 


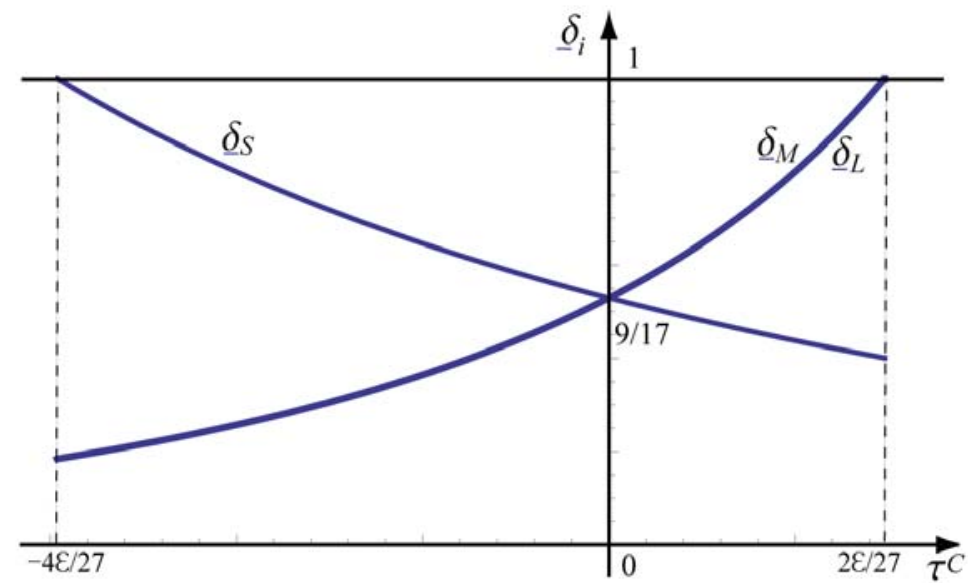

Figure 2: Loci of the minimum discount factors under full harmonization if $\theta=1$.

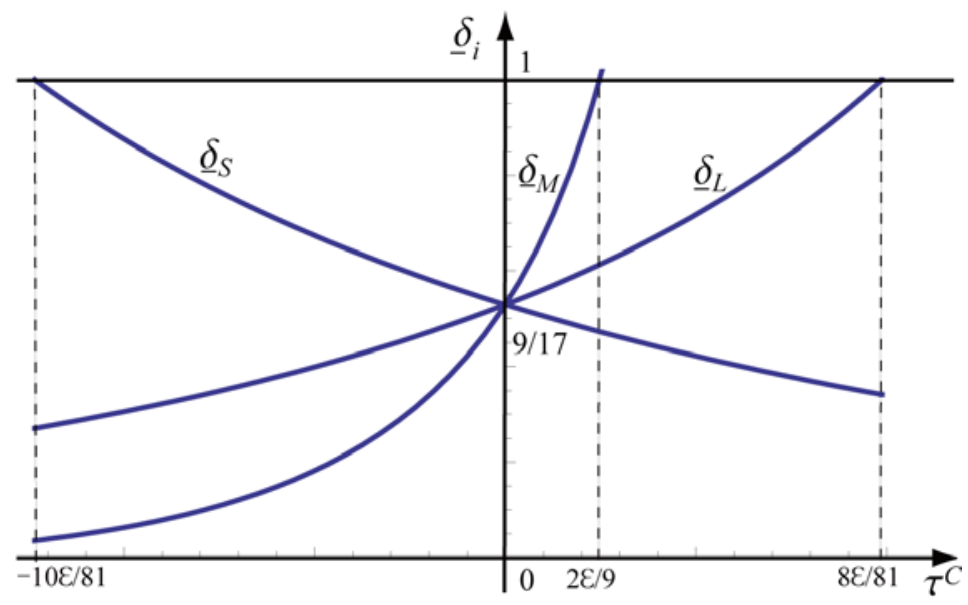

Figure 3: Loci of the minimum discount factors under full harmonization if $\theta=1 / 3$.

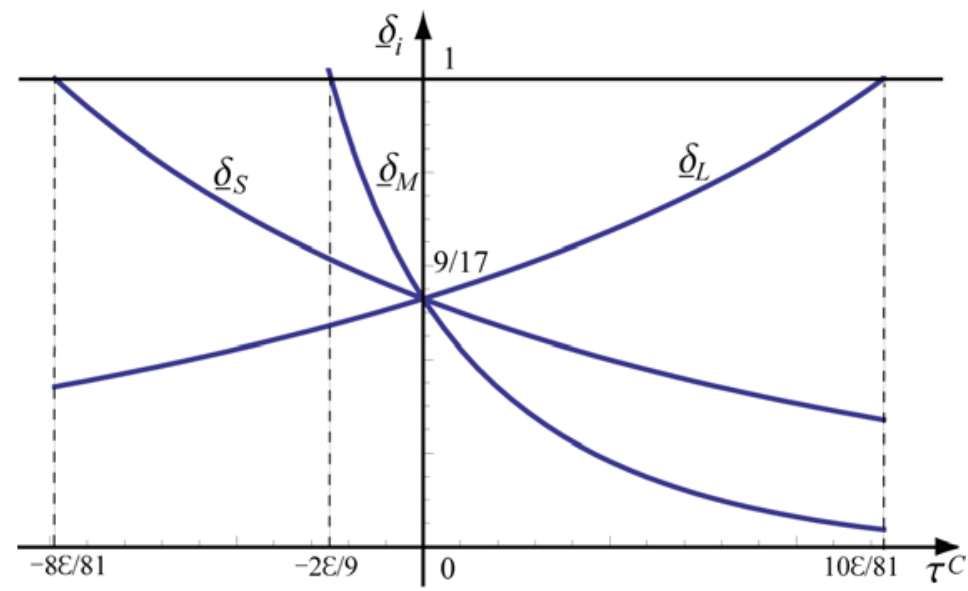

Figure 4: Loci of the minimum discount factors under full harmonization if $\theta=-1 / 3$. 


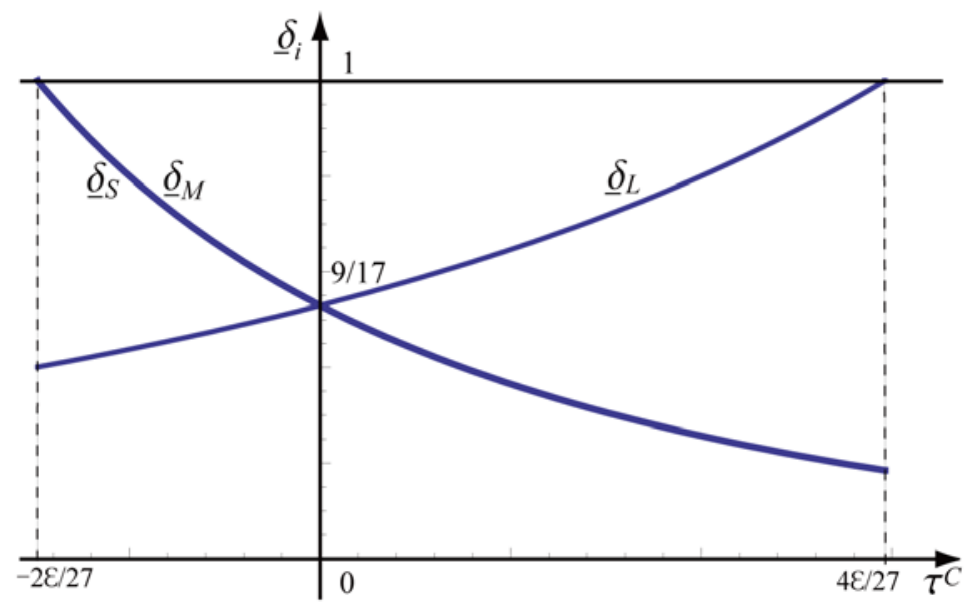

Figure 5: Loci of the minimum discount factors under full harmonization if $\theta=-1$.

of $\theta$ are given as follows:

$$
\begin{aligned}
& \delta^{*}=\left\{\begin{array}{ll}
\underline{\delta}_{S} & \text { for } \tau^{C} \in[-4 \varepsilon / 27,0] \\
\underline{\delta}_{L}=\underline{\delta}_{M} & \text { for } \tau^{C} \in[0,2 \varepsilon / 27]
\end{array}\right\} \quad \text { if } \theta=1, \\
& \delta^{*}=\left\{\begin{array}{ll}
\underline{\delta}_{S} & \text { for } \tau^{C} \in[-\varepsilon(3+\theta) / 27,0] \\
\underline{\delta}_{M} & \text { for } \tau^{C} \in[0,2 \varepsilon \theta / 27]
\end{array}\right\} \text { if } \theta \in(0,1), \\
& \delta^{*}=\underline{\delta}_{M}=1 \quad \text { if } \theta=0 \text {, } \\
& \delta^{*}=\left\{\begin{array}{ll}
\underline{\delta}_{M} & \text { for } \tau^{C} \in[2 \varepsilon \theta / 27,0] \\
\underline{\delta}_{L} & \text { for } \tau^{C} \in[0, \varepsilon(3-\theta) / 27]
\end{array}\right\} \quad \text { if } \theta \in(-1,0), \\
& \delta^{*}=\left\{\begin{array}{ll}
\underline{\delta}_{M}=\underline{\delta}_{S} & \text { for } \tau^{C} \in[-2 \varepsilon / 27,0] \\
\underline{\delta}_{L} & \text { for } \tau^{C} \in[0,4 \varepsilon / 27]
\end{array}\right\} \quad \text { if } \theta=-1 .
\end{aligned}
$$

These results are summarized as follows:

Proposition 1 (i) If all countries are sufficiently patient and unless the capital endowment of the medium country is equal to the average capital endowment of the large and small countries (i.e., $\theta \neq 0)$, then full tax harmonization can be sustained as a subgame perfect Nash equilibrium of the repeated tax competition game;

(ii) if the harmonized capital tax rate is set equal to zero and $\theta \neq 0$, then it is most likely that full tax harmonization prevails; and

(iii) if $\theta=0$, then it is impossible to sustain full tax harmonization.

When $\theta \in(0,1]$, the capital endowment of country $M$ is greater than the average capital endowment of countries $L$ and $S$, i.e., $\bar{k}_{A}<\bar{k}_{M} \leq \bar{k}_{L}$. As stated earlier, both countries $L$ and $M$ are capital exporters while only country $S$ is a capital importer. When the harmonized capital tax rate 
$\tau^{C}$ is positive, the per capita capital payment $r^{C}$ in (13) is lower than that in the Nash equilibrium (7), $r^{N}$, by the amount $\tau^{C}$, which implies that income transfers from the exporters (i.e., countries $L$ and $M$ ) to the importer (i.e., country $S$ ) take place under full tax harmonization. As a result, a higher harmonized tax rate depresses the utilities of countries $L$ and $M$ in the cooperative as well as deviation phases, which is confirmed by $\partial u_{L}^{C} / \partial \tau^{C}=-\varepsilon(3-\theta) / 3<0, \partial u_{M}^{C} / \partial \tau^{C}=-2 \varepsilon \theta / 3<0$, $\partial u_{L}^{D} / \partial \tau^{C}=\left[\tau^{C}-\varepsilon(3-\theta)\right] / 4<0$, and $\partial u_{M}^{D} / \partial \tau^{C}=\left(\tau^{C}-2 \varepsilon \theta\right) / 4<0$. It can also be easily shown that the reductions in $u_{L}^{C}$ and $u_{M}^{C}$ are larger in terms of absolute value than the reductions in $u_{L}^{D}$ and $u_{M}^{D}$, respectively, while $u_{L}^{N}$ and $u_{M}^{N}$ are not affected by the changes in $\tau^{C}$. Taken together, it can be seen from (25) that the incentives of the exporters (i.e., countries $L$ and $M$ ) to deviate will be enhanced by an increase in $\tau^{C}$. Moreover, as shown in the appendix of this paper, the incentive of country $M$ to deviate turns out to be stronger than that of country $L$ for a higher $\tau^{C}$, which makes the locus of the minimum discount factor $\underline{\delta}_{M}$ steeper compared to that of $\underline{\delta}_{L}$ for $\tau^{C} \geq 0$, as illustrated in Figs.2 and 3. This implies that $\delta^{*}=\underline{\delta}_{M}$ if $\tau^{C} \geq 0$. In contrast, a negative harmonized tax rate harms the capital importer (i.e., country $S$ ) through the higher capital payment $r^{C}$ in (13) compared to $r^{N}$ in (7), which results in income transfers from the importer to the exporters (i.e., countries $L$ and $M$ ), thus strengthening the incentive of country $S$ to deviate. As a result, $\delta^{*}=\underline{\delta}_{S}$ if $\tau^{C} \leq 0$, as shown in Figs.2 and 3 .

On the other hand, if $\theta \in[-1,0)$, i.e., $\bar{k}_{S} \leq \bar{k}_{M}<\bar{k}_{A}$, then country $L$ becomes a capital exporter and country $M$ becomes a capital importer. For the same reasoning as before, $\delta^{*}=\underline{\delta}_{M}$ when $\tau^{C}<0$, while $\delta^{*}=\underline{\delta}_{L}$ when $\tau^{C} \geq 0$. This is illustrated in Figs.4 and 5 .

Next, we will investigate how varying the difference in the capital endowments of countries $L$ and $S$ (which is measured by $2 \varepsilon$ ) or the ratio of the capital endowment of country $M$ to the average capital endowment of countries $L$ and $S$ (which is measured by $\theta$ ) affects the sustainability of full tax harmonization. For given values of $\tau^{C}$ and $\varepsilon$, a higher value of $\theta$ makes counter-clockwise turns of the loci $\underline{\delta}_{L}$ and $\underline{\delta}_{S}$, while making a clockwise turn of the locus $\underline{\delta}_{M}$ around the intersection point (0, 9/17), as illustrated in Figs.10, 11, and 12 in the appendix of this paper. As a result, except for the intersection point, the locus $\delta^{*}$ shifts upward with $\theta$ when $\theta \in[-1,0)$, whereas it shifts downward with $\theta$ if $\theta \in(0,1]$. On the other hand, as $\theta$ becomes closer to 0 , the range of $\tau^{C}$ given by (18) becomes more narrow, thus making full harmonization more difficult. In the limit where the capital endowment of country $M$ is equal to the average capital endowment of countries $L$ and $S$ (i.e., $\theta=0$ ), full harmonization is impossible because $\delta^{*}=\underline{\delta}_{M}=1$.

For any given value of $\tau^{C}$ and $\theta \neq 0$, a higher value of $\varepsilon$ makes a clockwise turn of the locus $\underline{\delta}_{L}$ 
and a counter-clockwise turn of the locus $\underline{\delta}_{S}$ around the intersection point. In contrast, $\underline{\delta}_{M}$ moves in the counter-clockwise direction with $\varepsilon$ when $\theta \in[-1,0)$, while it moves in the clockwise direction with $\varepsilon$ if $\theta \in(0,1]$ [see (A9), (A10), and (A11) in the appendix]. From the above and (29), we get that an increase in $\varepsilon$ tends to enlarge the range of $\tau^{C}$ given by (18), thus making full harmonization easier. To sum up, we have:

Proposition 2 (i) For given values of $\tau^{C} \neq 0$ lying in (18) and the difference in the capital endowments of large and small countries (i.e., $2 \varepsilon$ ), the closer the capital endowment of the median country to the average capital endowment of the large and small countries (i.e., $\theta \rightarrow 0$ ), the less likely is full tax harmonization to prevail. Conversely, the more distant the capital endowment of the median country from the average capital endowment of the large and small countries (i.e., $\theta \rightarrow \pm 1$ ), the more likely is full tax harmonization to prevail;

(ii) for given values of $\tau^{C} \neq 0$ lying in (18) and $\theta \neq 0$, an increase in the difference in the capital endowments of countries $L$ and $S$ (i.e., $2 \varepsilon$ ) makes full tax harmonization more likely to prevail; and (iii) if $\tau^{C}=0$ and $\theta \neq 0$, then the willingness of every country to sustain full tax harmonization is unaffected by the changes in $\theta$ and $\varepsilon$.

Proposition 2 implies that the sustainability of full harmonization depends on the degree of asymmetry, which is measured by $\varepsilon$, the harmonized tax rate $\tau^{C}$, and the capital endowment of the median country relative to that of the large country or small country, which is measured by $\theta$. The effects of $\varepsilon$ and $\tau^{C}$ on the likelihood of tax harmonization are consistent with those found by Itaya et al. (2008), although there is no median country in their model. Adding one country to their two-country models would bring about new implications on how asymmetry affects the sustainability of tax harmonization. If the capital endowment of the median country becomes closer to the average capital endowment of the large and small countries, tax harmonization is less likely to prevail. Nevertheless, there is always a certain range of $\tau^{C}$ (i.e., the interval of positive length) wherein the threshold value of the discount factor $\delta^{*}$ is equal to $\underline{\delta}_{M}$, as seen in Figs.2, 3, 4 , and 5. When the capital endowments of the three countries are set equally apart (i.e., $\theta=0$ ), full tax harmonization is impossible. In this case, country $M$ does not engage in any capital trade, and hence its welfare remains the same as that at the Nash equilibrium in (10).

These results also stand in sharp contrast to Cardarelli et al. (2002) and Catenaro and Vidal (2006) who obtained using a two-country model that the small country has a stronger incentive to deviate from tax harmonization, since in our three-country model the median country may have the 
strongest incentive to deviate.

\section{Partial Harmonization}

In this section, we investigate the conditions under which partial tax harmonization is sustained. In what follows, we suppose that a subset of any two countries, $G$, agrees to cooperate on the setting of its common tax rate, while the third country chooses its tax rate noncooperatively. Hence, there are three possible tax unions $\{L M, M S, L S\}$ wherein tax harmonization is implemented.

\subsection{Partial Harmonization between $L$ and $M$}

First, consider a partial union consisting of countries $L$ and $M$ that agree to jointly choose their tax rates in a coordinated way in order to maximize the sum of their utilities represented by $W(L M) \equiv$ $u_{L}+u_{M}=f\left(k_{L}^{*}\right)+f\left(k_{M}^{*}\right)+r^{*}\left(k_{S}^{*}-\bar{k}_{S}\right)$. The first-order conditions with respect to $\tau_{L}$ and $\tau_{M}$ are

$$
\frac{\partial W(L M)}{\partial \tau_{i}}=f^{\prime}\left(k_{i}^{*}\right) \frac{\partial k_{i}^{*}}{\partial \tau_{i}}+f^{\prime}\left(k_{j}^{*}\right) \frac{\partial k_{j}^{*}}{\partial \tau_{i}}+r^{*} \frac{\partial k_{S}^{*}}{\partial \tau_{i}}+\frac{\partial r^{*}}{\partial \tau_{i}}\left(k_{S}^{*}-\bar{k}_{S}\right)=0, \quad i, j=L, M, \quad i \neq j .
$$

By substituting (1), (2), and (3) into the above conditions, the best-response functions of the member countries $L$ and $M$ are derived as follows:

$$
\tau_{i}=\frac{2}{7}\left[\tau_{j}+\tau_{S}-\varepsilon(3+\theta)\right], \quad i, j=L, M, \quad i \neq j,
$$

which immediately yields $\tau_{L}=\tau_{M}$, i.e., the harmonized capital tax rate should be equalized within the tax union. On the other hand, country $S$ that is outside the union chooses its tax rate so as to maximize its utility noncooperatively and independently, which implies that country $S$ behaves according to (5). By solving these best-response functions simultaneously, we obtain the harmonized tax rate, $\tau^{C}(L M)$, and the tax rate chosen by country $S, \tau_{S}^{C}(L M)$, in the subgroup Nash equilibrium (see Konrad and Schjelderup, 1999):

$$
\tau^{C}(L M)=-\frac{1}{3} \varepsilon(3+\theta)<0 \text { and } \tau_{S}^{C}(L M)=\frac{1}{6} \varepsilon(3+\theta)>0 .
$$

It should be noted that the harmonized tax rate is uniquely determined by the parameters $\varepsilon$ and $\theta$, unlike in the case of full tax harmonization. Substituting (30) into (1) and (2) yields the following equilibrium net return and amount of capital demanded in country $i=L, M, S$, in the cooperative 
phase:

$$
\begin{aligned}
r^{C}(L M) & =a-2 \bar{k}_{A}+\frac{1}{2} \varepsilon(1-\theta), \\
k_{L}^{C}(L M) & =k_{M}^{C}(L M)=\bar{k}_{A}+\frac{1}{12} \varepsilon(3+5 \theta) \text { and } k_{S}^{C}(L M)=\bar{k}_{A}-\frac{1}{6} \varepsilon(3-\theta) .
\end{aligned}
$$

Under the partial tax harmonization between countries $L$ and $M$, it follows from (30) and (32) that country $L$ exports capital with subsidies (i.e., $\tau^{C}(L M)<0$ ) while country $S$ imports capital with taxes (i.e., $\tau_{S}^{C}(L M)>0$ ). Although country $M$ agrees to subsidize capital (i.e., $\tau^{C}(L M)<0$ ), it can be either a capital importer or capital exporter; more precisely, country $M$ becomes either an importer if $\theta \in[-1,3 / 7)$ or an exporter if $\theta \in(3 / 7,1]$, while its net trade of capital is equal to zero if $\theta=3 / 7$. As shown below, however, due to the participation constraint, country $M$ has to be a capital exporter when joining the tax union.

The utility levels of the member countries $L$ and $M$ are respectively given as follows:

$$
\begin{aligned}
u_{L}^{C}(L M) & =\left(a-\bar{k}_{A}\right) \bar{k}_{A}+\left(a-2 \bar{k}_{A}\right) \varepsilon+\frac{1}{144} \varepsilon^{2}\left(5 \theta^{2}-114 \theta+45\right), \\
u_{M}^{C}(L M) & =\left(a-\bar{k}_{A}\right) \bar{k}_{A}+\left(a-2 \bar{k}_{A}\right) \varepsilon \theta-\frac{1}{144} \varepsilon^{2}\left(67 \theta^{2}-30 \theta+27\right) .
\end{aligned}
$$

By utilizing (9), (10), (33), and (34), the participation constraints for the respective countries are as follows:

$$
\begin{aligned}
u_{L}^{C}(L M)-u_{L}^{N} & =-\frac{1}{1296} \varepsilon^{2}\left(83 \theta^{2}+258 \theta-549\right)>0 \text { for } \theta \in[-1,1] \\
u_{M}^{C}(L M)-u_{M}^{N} & =\frac{1}{1296} \varepsilon^{2}\left(181 \theta^{2}+270 \theta-243\right) \geq 0 \text { for } \theta \in\left[\frac{-135+144 \sqrt{3}}{181}, 1\right] .
\end{aligned}
$$

These inequalities imply that country $L$ has an incentive to take part in the tax union for any value of $\theta$, while country $M$ has the incentive only if $\theta>(-135+144 \sqrt{3}) / 181 \fallingdotseq 0.632$. Although country $M$ is a capital exporter for $\theta \in(3 / 7,1]$, it no longer wants to participate in the union for $\theta \in(3 / 7$, $(-135+144 \sqrt{3}) / 181]$.

To identify the conditions under which the partial harmonization between countries $L$ and $M$ is sustained, we need to calculate the best-deviation tax rates of the respective countries, denoted by $\tau_{i}^{D}(L M), i=L, M$, which is chosen by maximizing $u_{i}$ given that the other member country follows $\tau^{C}(L M)$. Setting $\tau_{j}=\tau^{C}(L M)$ for $j=L, M$ and $\tau_{S}=\tau_{S}^{C}(L M)$ in (5) yields the following 
best-deviation tax rates:

$$
\begin{aligned}
\tau_{L}^{D}(L M) & =-\frac{1}{48} \varepsilon(39-11 \theta) \\
\tau_{M}^{D}(L M) & =-\frac{1}{48} \varepsilon(3+25 \theta)
\end{aligned}
$$

When country $L$ deviates from $\tau^{C}(L M)$ by choosing $\tau_{L}^{D}(L M)$, while countries $M$ and $S$ continue to choose $\tau^{C}(L M)$ and $\tau_{S}^{C}(L M)$, respectively, the net return on capital, the capital demand in country $L$, and the corresponding utility level are obtained by (1), (2), (30), and (37):

$$
\begin{aligned}
r_{L}^{D}(L M) & =a-2 \bar{k}_{A}+\frac{1}{16} \varepsilon(7-11 \theta), \\
k_{L}^{D}(L M) & =\bar{k}_{A}+\frac{1}{48} \varepsilon(9+11 \theta), \\
u_{L}^{D}(L M) & =\left(a-\bar{k}_{A}\right) \bar{k}_{A}+\left(a-2 \bar{k}_{A}\right) \varepsilon+\frac{1}{1152} \varepsilon^{2}\left(121 \theta^{2}-858 \theta+369\right) .
\end{aligned}
$$

Similarly, when country $M$ deviates from $\tau^{C}(L M)$ by choosing $\tau_{M}^{D}(L M)$, while countries $L$ and $S$ continue to choose $\tau^{C}(L M)$ and $\tau_{S}^{C}(L M)$, respectively, we have the following:

$$
\begin{aligned}
& r_{M}^{D}(L M)=a-2 \bar{k}_{A}+\frac{1}{16} \varepsilon(3-7 \theta), \\
& k_{M}^{D}(L M)=\bar{k}_{A}-\frac{1}{48} \varepsilon(3-23 \theta), \\
& u_{M}^{D}(L M)=\left(a-\bar{k}_{A}\right) \bar{k}_{A}+\left(a-2 \bar{k}_{A}\right) \varepsilon \theta-\frac{1}{1152} \varepsilon^{2}\left(527 \theta^{2}-150 \theta-9\right) .
\end{aligned}
$$

From (9), (10), (25), (33), (34), (39), and (40), we obtain the minimum discount factors of countries $L$ and $M$ in the partial union as follows:

$$
\begin{aligned}
\underline{\delta}_{L}(L M) & =\frac{u_{L}^{D}(L M)-u_{L}^{C}(L M)}{u_{L}^{D}(L M)-u_{L}^{N}}=\frac{81(1+3 \theta)^{2}}{(21-\theta)(213-65 \theta)} \\
\underline{\delta}_{M}(L M) & =\frac{u_{M}^{D}(L M)-u_{M}^{C}(L M)}{u_{M}^{D}(L M)-u_{M}^{N}}=\frac{81(5-\theta)^{2}}{(9+11 \theta)(9+139 \theta)} .
\end{aligned}
$$

Inspection of (41) and (42) reveals that as long as $\theta$ satisfies the participation constraint (36), the partial tax harmonization between countries $L$ and $M$ is sustainable, i.e., there exists a positive interval of $\theta$ such that $\underline{\delta}_{i}(L M)<1, i=L, M$; see Fig.6), and also that the incentives of these countries to cooperate are critically affected by the capital endowment of country $M$ relative to the average capital endowment between countries $L$ and $S$ (i.e., $\theta$ ). Moreover, it is straightforward to show that over the range of $\theta$ satisfying the participation constraint $(36), \underline{\delta}_{L}(L M)$ in (41) is increasing 


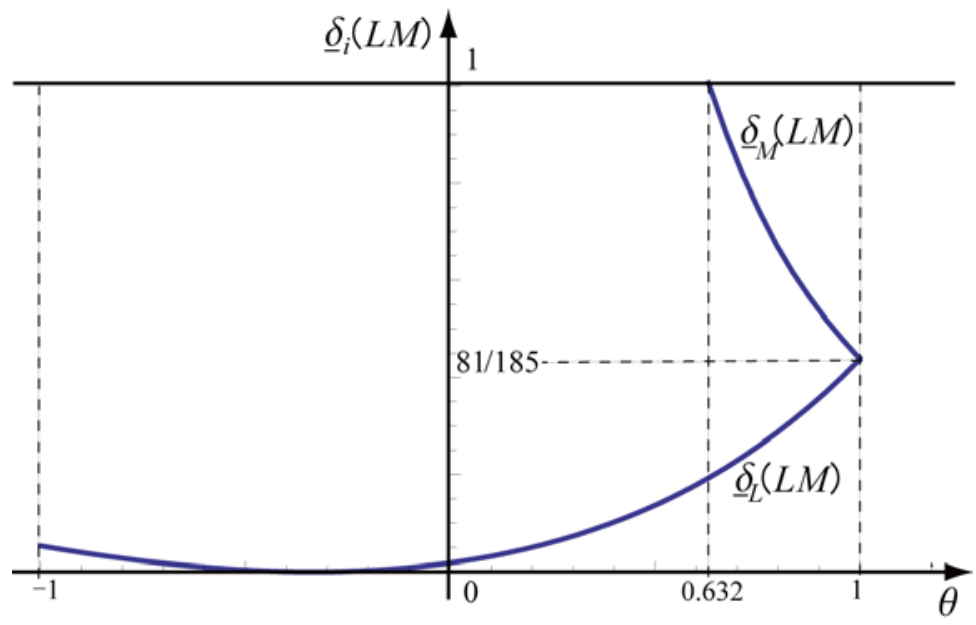

Figure 6: Loci of the minimum discount factors of countires $L$ and $M$.

in $\theta$, while $\underline{\delta}_{M}(L M)$ in (42) is decreasing in $\theta$, and that they intersect each other at $\theta=1$; that is, $\underline{\delta}_{L}(L M)=\underline{\delta}_{M}(L M)=81 / 185$ at $\theta=1$. Fig.6 illustrates the graphs of $\underline{\delta}_{L}(L M)$ and $\underline{\delta}_{M}(L M)$. This figure implies that partial harmonization is possible when the actual (common) discount factor $\delta$ of both member countries is greater than $\underline{\delta}_{M}(L M)$ at any value of $\theta \in((-135+144 \sqrt{3}) / 181,1]$.

These observations lead to the following proposition:

Proposition 3 (i) If the large and median countries are sufficiently patient and the ratio of $\bar{k}_{M}-\bar{k}_{A}$ to $\bar{k}_{L}-\bar{k}_{A}\left(\right.$ or $\left.\bar{k}_{A}-\bar{k}_{S}\right)$ (i.e., $\left.\theta\right)$ is greater than $(-135+144 \sqrt{3}) / 181$, then partial tax harmonization between them can be sustained as a subgame perfect Nash equilibrium of the repeated tax competition game;

(ii) as $\theta$ increases from $(-135+144 \sqrt{3}) / 181$ to 1 , it is more likely that partial tax harmonization prevails;

(iii) when $\theta=1$, it is most likely that partial tax harmonization prevails; and

(iv) the sustainability of partial tax harmonization is independent of the difference in the capital endowments of the large and small countries (i.e., $2 \varepsilon$ ).

To understand the intuition behind Proposition 3 suppose that $\theta$ increases as long as $\theta \geq(-135+$ $144 \sqrt{3}) / 181 \cong 0.632>0$ (see Fig.6 also). Since both countries $L$ and $M$ are exporters, so is the tax union; consequently, as seen from (30), the union is willing to choose a negative harmonized tax rate in order to raise their remuneration on capital. The increased total supply of capital associated with a larger $\theta$ depresses $r^{C}(L M)$, which is implied by (31). In response, the tax union lowers $\tau^{C}(L M)$ in order to raise the remuneration on capital (i.e., $r^{C}(L M)$ ), while country $S$ raises $\tau_{S}^{C}(L M)$ in order 
to reduce capital payments (recall that the tax rates are strategic complements). According to (31), ${ }_{r}^{C}(L M)$ has to fall, which in turn stimulates the capital demands of countries $L$ and $M$. These impacts together lead to a decrease in their remuneration on capital, ${ }^{C}(L M)\left[\bar{k}_{i}-k_{i}^{C}(L M)\right], i=L$, $M$, while the production of output, $f\left(k_{i}^{C}(L M)\right), i=L, M$, is expanded by the increased $k_{i}^{C}(L M)$. As a result, although the overall effects on $u_{i}^{C}(L M) \equiv f\left(k_{i}^{C}(L M)\right)+r^{C}(L M)\left[\bar{k}_{i}-k_{i}^{C}(L M)\right], i=L$, $M$, appear to be ambiguous, it can be easily shown that

$$
\begin{aligned}
\frac{\partial u_{L}^{C}(L M)}{\partial \theta} & =\frac{1}{72} \varepsilon^{2}(5 \theta-57)<0, \\
\frac{\partial u_{M}^{C}(L M)}{\partial \theta} & =\varepsilon\left[a-2 \bar{k}_{A}+\frac{1}{72} \varepsilon(15-67 \theta)\right] \gtreqless 0 .
\end{aligned}
$$

Since country $L$ exports capital more than country $M$, the negative terms of trade effect caused by a reduced $r^{C}(L M)$ on the remuneration on capital for country $L$ overweighs its positive output effect, thereby reducing $u_{L}^{C}(L M)$. Moreover, since the reduction in $u_{L}^{C}(L M)$ is absolutely larger than the reduction in $u_{L}^{N}$ in (9), which is confirmed by differentiating (35) and (36) with respect to $\theta$ :

$$
\begin{gathered}
\frac{\partial u_{L}^{C}(L M)}{\partial \theta}-\frac{\partial u_{L}^{N}}{\partial \theta}=-\frac{1}{648} \varepsilon^{2}(83 \theta+129)<0 \\
\frac{\partial u_{M}^{C}(L M)}{\partial \theta}-\frac{\partial u_{M}^{N}}{\partial \theta}=\frac{1}{648} \varepsilon^{2}(181 \theta+135)>0 .
\end{gathered}
$$

This implies that the minimum discount factor of country $L$ in (41) rises with $\theta$, while that of country $M$ in (42) falls with $\theta$, as illustrated in Fig. $6 .{ }^{4}$ The reason for these opposite responses is that whether or not the negative terms of trade effect caused by the increased $\theta$ has a dominant effect on $u_{i}^{C}(L M)$, $i=L, M$, crucially depends on the amount of capital exported by the respective countries; hence, country $L$ is more damaged by the decreased net return on capital compared to country $M$, because the amount of capital exported by country $L$ is larger than that by country $M$.

\subsection{Partial Harmonization between $M$ and $S$}

Next, we consider a partial union consisting of countries $M$ and $S$. The member countries of the tax union jointly choose their capital tax rates in order to maximize the sum of the representative residents' utilities represented by $W(M S) \equiv u_{M}+u_{S}=f\left(k_{M}^{*}\right)+f\left(k_{S}^{*}\right)+r^{*}\left(k_{L}^{*}-\bar{k}_{L}\right)$. The first-order

\footnotetext{
${ }^{4}$ Although we find that $u_{i}^{D}(L M), i=L, M$, decreases with $\theta$, we can show that (43) and (44) are the major determinants of the effects of the changes in $\theta$ on the minimum discount factors given by (41) and (42), respectively.
} 
conditions with respect to $\tau_{M}$ and $\tau_{S}$ are given by

$$
\frac{\partial W(M S)}{\partial \tau_{i}}=f^{\prime} k_{i}^{*}\left(k_{L}^{*}-\bar{k}_{L}\right)=0, \quad i, j=M, S, \quad i \neq j .
$$

Substituting (1), (2), and (3) into the above conditions and rearranging yields the following bestresponse functions of country $i$ in the union:

$$
\tau_{i}=\frac{2}{7}\left[\tau_{j}+\tau_{L}+\varepsilon(3-\theta)\right], \quad i, j=M, S, \quad i \neq j,
$$

which implies that $\tau_{M}=\tau_{S}$. The non-member country $L$, on the other hand, chooses its own tax rate according to (5) unilaterally. By solving these best-response functions simultaneously, we obtain the unique harmonized common tax rate and the tax rate chosen by country $L$ in the subgroup Nash equilibrium, respectively:

$$
\tau^{C}(M S)=\frac{1}{3} \varepsilon(3-\theta)>0 \text { and } \tau_{L}^{C}(M S)=-\frac{1}{6} \varepsilon(3-\theta)<0 .
$$

Substituting (45) into (1) and (2) yields the equilibrium net return and the amount of capital demanded in country $i$, respectively:

$$
\begin{aligned}
r^{C}(M S) & =a-2 \bar{k}_{A}-\frac{1}{2} \varepsilon(1+\theta) \\
k_{L}^{C}(M S) & =\bar{k}_{A}+\frac{1}{6} \varepsilon(3+\theta) \text { and } k_{M}^{C}(M S)=k_{S}^{C}(M S)=\bar{k}_{A}-\frac{1}{12} \varepsilon(3-5 \theta) .
\end{aligned}
$$

It follows from (45) and (47) that the non-member country $L$ always exports capital with subsidy, while the member country $S$ always imports capital with taxation; on the other hand, the member country $M$ becomes an importer if $\theta \in[-1,-3 / 7)$ and an exporter if $\theta \in(-3 / 7,1]$, with its net trade of capital being equal to zero if $\theta=-3 / 7$.

Furthermore, we need to identify an exact range of $\theta$ that satisfies the participation constraint for the member countries. The utility levels of the member countries $M$ and $S$ are, respectively, given as follows:

$$
\begin{aligned}
& u_{M}^{C}(M S)=\left(a-\bar{k}_{A}\right) \bar{k}_{A}+\left(a-2 \bar{k}_{A}\right) \varepsilon \theta-\frac{1}{144} \varepsilon^{2}\left(67 \theta^{2}+30 \theta+27\right), \\
& u_{S}^{C}(M S)=\left(a-\bar{k}_{A}\right) \bar{k}_{A}-\left(a-2 \bar{k}_{A}\right) \varepsilon+\frac{1}{144} \varepsilon^{2}\left(5 \theta^{2}+114 \theta+45\right) .
\end{aligned}
$$


By utilizing (10), (11), (48), and (49), we obtain the participation constraints for countries $M$ and $S$, respectively:

$$
\begin{aligned}
& u_{M}^{C}(M S)-u_{M}^{N}=\frac{1}{1296} \varepsilon^{2}\left(181 \theta^{2}-270 \theta-243\right) \geq 0 \text { for } \theta \in\left[-1, \frac{135-144 \sqrt{3}}{181}\right], \\
& u_{S}^{C}(M S)-u_{S}^{N}=-\frac{1}{1296} \varepsilon^{2}\left(83 \theta^{2}-258 \theta-549\right)>0 \text { for } \theta \in[-1,1] .
\end{aligned}
$$

Eqs.(47) and (50) together reveal that country $M$ has to be a capital importer when joining the tax union; however, when $\theta \in[(135-144 \sqrt{3}) / 181,-3 / 7)$, though country $M$ is still a capital importer, it no longer wants to participate in the union. It can be seen from (45) and (46) that a smaller $\theta$ (i.e., $\theta \in[-1,(135-144 \sqrt{3}) / 181)$ ) raises the (positive) harmonized tax rate $\tau^{C}(M S)$ as well as the net return $r^{C}(M S)$. Although the positive association between $\tau^{C}(M S)$ and $r^{C}(M S)$ might be counter-intuitive, it stems from the fact that the positive effect of the decreased total supply of capital would overweigh the negative terms of trade effect caused by a higher $\tau^{C}(M S)$.

The best-deviation tax rates of countries $M$ and $S$ will be chosen by maximizing $u_{i}$ given that the other member country follows the harmonized tax rate given by (45). Setting $\tau_{j}=\tau^{C}(M S)$ and $\tau_{L}=\tau_{L}^{C}(M S)$ in (5) yields the best-deviation tax rates of countries $M$ and $S$, respectively:

$$
\begin{aligned}
\tau_{M}^{D}(M S) & =\frac{1}{48} \varepsilon(3-25 \theta), \\
\tau_{S}^{D}(M S) & =\frac{1}{48} \varepsilon(39+11 \theta) .
\end{aligned}
$$

When country $M$ deviates from $\tau^{C}(M S)$ by choosing $\tau_{M}^{D}(M S)$, and countries $L$ and $S$ follow $\tau_{L}^{C}(M S)$ and $\tau^{C}(M S)$, respectively, the net return on capital, the capital demand in country $M$, and the corresponding utility level are, respectively, obtained by making use of (1), (2), (45), and (52):

$$
\begin{aligned}
r_{M}^{D}(M S) & =a-2 \bar{k}_{A}-\frac{1}{16} \varepsilon(3+7 \theta), \\
k_{M}^{D}(M S) & =\bar{k}_{A}+\frac{1}{48} \varepsilon(3+23 \theta), \\
u_{M}^{D}(M S) & =\left(a-\bar{k}_{A}\right) \bar{k}_{A}+\left(a-2 \bar{k}_{A}\right) \varepsilon \theta-\frac{1}{1152} \varepsilon^{2}\left(527 \theta^{2}+150 \theta-9\right) .
\end{aligned}
$$




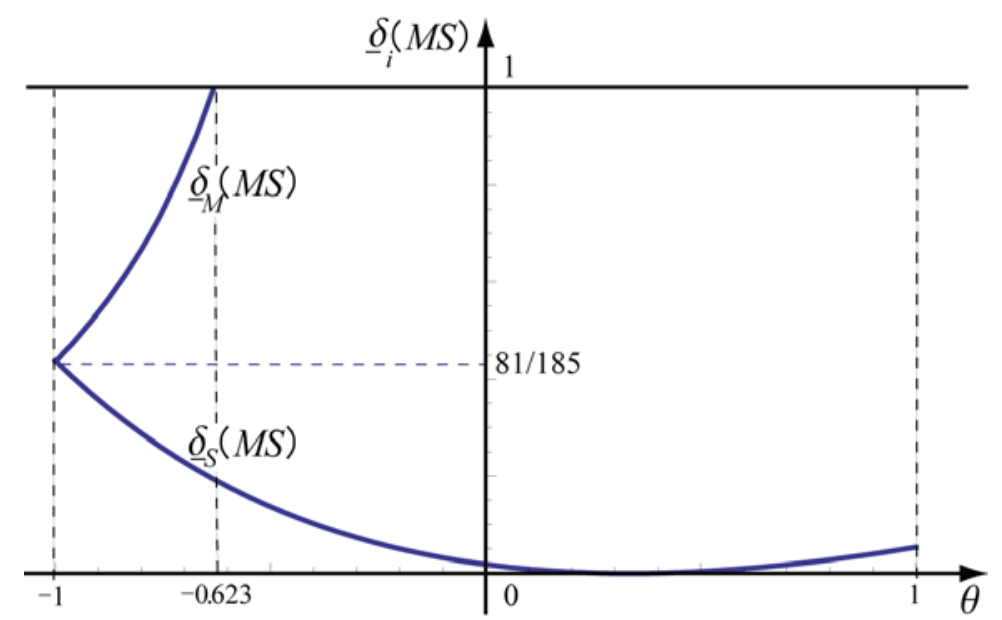

Figure 7: Loci of the minimum discount factors of countires $M$ and $S$.

Similarly, when country $S$ deviates from $\tau^{C}(M S)$ by choosing $\tau_{S}^{D}(M S)$, we have the following:

$$
\begin{aligned}
r_{S}^{D}(M S) & =a-2 \bar{k}_{A}-\frac{1}{16} \varepsilon(7+11 \theta) \\
k_{S}^{D}(M S) & =\bar{k}_{A}-\frac{1}{48} \varepsilon(9-11 \theta) \\
u_{S}^{D}(M S) & =\left(a-\bar{k}_{A}\right) \bar{k}_{A}-\left(a-2 \bar{k}_{A}\right) \varepsilon+\frac{1}{1152} \varepsilon^{2}\left(121 \theta^{2}+858 \theta+369\right) .
\end{aligned}
$$

By utilizing (10), (11), (25), (48), (49), (54), and (55), we obtain the minimum discount factors of the member countries $M$ and $S$, respectively:

$$
\begin{aligned}
\underline{\delta}_{M}(M S) & =\frac{u_{M}^{D}(M S)-u_{M}^{C}(M S)}{u_{M}^{D}(M S)-u_{M}^{N}}=\frac{81(5+\theta)^{2}}{(9-11 \theta)(9-139 \theta)}, \\
\underline{\delta}_{S}(M S) & =\frac{u_{S}^{D}(M S)-u_{S}^{C}(M S)}{u_{S}^{D}(M S)-u_{S}^{N}}=\frac{81(1-3 \theta)^{2}}{(21+\theta)(213+65 \theta)} .
\end{aligned}
$$

As long as $\theta$ satisfies the participation constraint (50), the partial harmonization between $M$ and $S$ is sustainable, i.e., there exists a positive interval of $\theta$ such that $\underline{\delta}_{i}(M S)<1, i=M, S$; see Fig.7). Furthermore, we can show that $\underline{\delta}_{M}(M S)$ in (56) is increasing in $\theta$, while $\underline{\delta}_{S}(M S)$ in (57) is decreasing in $\theta$, and that they intersect each other at $\theta=-1$; that is, $\underline{\delta}_{M}(M S)=\underline{\delta}_{S}(M S)=81 / 185$ at $\theta=-1$. Fig.7 illustrates the graphs of $\underline{\delta}_{M}(M S)$ and $\underline{\delta}_{S}(M S)$.

These observations lead to the following proposition:

Proposition 4 (i) If the median and small countries are sufficiently patient, then partial tax harmonization between them can be sustained as a subgame perfect Nash equilibrium of the repeated tax 
competition game;

(ii) as the capital endowment of the median country becomes closer to that of the small country (i.e., $\theta$ decreases from $(135-144 \sqrt{3}) / 181$ to -1$)$, it is more likely that partial tax harmonization prevails; (iii) when the capital endowment of the median country is equal to that of the small country (i.e., $\theta=-1)$, it is most likely that partial tax harmonization prevails; and

(iv) the sustainability of partial tax harmonization is independent of the difference in the capital endowments of the large and small countries (i.e., $2 \varepsilon$ ).

Suppose that $\theta$ decreases over the interval $[-1,(135-144 \sqrt{3}) / 181 \cong-0.623]$ (see (7) also). Since in this case, the tax union as a whole is a capital importer (since both countries $M$ and $S$ are capital importers), the member countries agree to levy capital by a positive harmonized tax rate. Since the decreased total supply of capital associated with a smaller $\theta$ causes $r^{C}(M S)$ to increase, the union raises $\tau^{C}(M S)$ to decrease its capital payment, while country $L$ lowers $\tau_{L}^{C}(M S)$ to increase its remuneration on capital, which is implied by (45) (since the tax rates are strategic complementary). It follows from (46) that $r^{C}(M S)$ increases thereby depressing the demand for capital in countries $M$ and $S$. As a result, their capital payments, $r^{C}(M S)\left[k_{i}^{C}(M S)-\bar{k}_{i}\right], i=M, S$, may or may not decrease, while the outputs of countries $M$ and $S, f\left(k_{i}^{C}(M S)\right), i=M, S$, unambiguously decrease. Taken together, it can be shown that

$$
\begin{aligned}
\frac{\partial u_{M}^{C}(M S)}{\partial \theta} & =\varepsilon\left[a-2 \bar{k}_{A}-\frac{1}{72} \varepsilon(67 \theta+15)\right] \gtreqless 0, \\
\frac{\partial u_{S}^{C}(M S)}{\partial \theta} & =\frac{1}{72} \varepsilon^{2}(5 \theta+114)>0 .
\end{aligned}
$$

Since country $S$ imports more capital than country $M$, the terms of trade effect caused by an increasing $r^{C}(M S)$ has a dominant effect on $u_{S}^{C}(M S)$; consequently, the capital payment borne by country $S$ increases as $\theta$ is lowered and thus $u_{S}^{C}(M S)$ unambiguously decreases. In contrast, the capital payment borne by country $M$ may increase in response to a lower $\theta$, and thus the overall impact on $u_{M}^{C}(M S)$ would be ambiguous.

Nevertheless, differentiating (50) and (51) with respect to $\theta$ yields

$$
\begin{aligned}
& \frac{\partial u_{M}^{C}(M S)}{\partial \theta}-\frac{\partial u_{M}^{N}}{\partial \theta}=\frac{1}{648} \varepsilon^{2}(181 \theta-135)<0, \\
& \frac{\partial u_{S}^{C}(M S)}{\partial \theta}-\frac{\partial u_{S}^{N}}{\partial \theta}=-\frac{1}{648} \varepsilon^{2}(83 \theta-129)>0,
\end{aligned}
$$


which together with (56) and (57), implies that the minimum discount factor of country $M$ (country $S$ ) becomes smaller (larger), as illustrated in Fig.7. Since the negative terms of trade effect associated with a smaller $\theta$ discourages the incentive of country $S$ to deviate. In contrast, since for country $M$ the negative terms of trade effect is not so strong, the impact on $u_{M}^{C}(M S)$ in terms of absolute value is less than that on $u_{M}^{N}(M S)$, thereby weakening the incentive to deviate. In short, whether or not the changes in $\theta$ enhance the incentives of the member countries to deviate crucially depends on the magnitude of the terms of trade effect, which is positively proportional to the amount of capital imported by the member countries.

\subsection{Partial Harmonization between $L$ and $S$}

Finally, consider a partial union consisting of countries $L$ and $S$. These countries jointly and cooperatively choose capital tax rates in order to maximize the sum of their utilities represented by $W(L S) \equiv u_{L}+u_{S}=f\left(k_{L}^{*}\right)+f\left(k_{S}^{*}\right)+r^{*}\left(k_{M}^{*}-\bar{k}_{M}\right)$. The first-order conditions with respect to $\tau_{L}$ and $\tau_{S}$ are

$$
\frac{\partial W(L S)}{\partial \tau_{i}}=f^{\prime}\left(k_{i}^{*}\right) \frac{\partial k_{i}^{*}}{\partial \tau_{i}}+f^{\prime}\left(k_{j}^{*}\right) \frac{\partial k_{j}^{*}}{\partial \tau_{i}}+r^{*} \frac{\partial k_{M}^{*}}{\partial \tau_{i}}+\frac{\partial r^{*}}{\partial \tau_{i}}\left(k_{M}^{*}-\bar{k}_{M}\right)=0, \quad i, j=L, S, \quad i \neq j,
$$

which, respectively, yield the following best-response functions of the member countries:

$$
\tau_{i}=\frac{2}{7}\left(\tau_{j}+\tau_{M}+2 \varepsilon \theta\right), \quad i, j=L, S, \quad i \neq j
$$

The non-member country $M$, on the other hand, chooses its tax rate in accordance with (5) unilaterally. By solving these best-response functions simultaneously, we obtain the unique harmonized common tax rate, $\tau^{C}(L S)$, and the tax rate chosen by country $M, \tau_{M}^{C}(L S)$, in the subgroup Nash equilibrium:

$$
\tau^{C}(L S)=\frac{2}{3} \varepsilon \theta \gtreqless 0 \text { and } \tau_{M}^{C}(L S)=-\frac{1}{3} \varepsilon \theta \lesseqgtr 0 .
$$

Substituting (58) into (1) and (2) yields the net return and the capital demand in country $i$ :

$$
\begin{aligned}
& r^{C}(L S)=a-2 \bar{k}_{A}-\varepsilon \theta, \\
& k_{L}^{C}(L S)=k_{S}^{C}(L S)=\bar{k}_{A}+\frac{1}{6} \varepsilon \theta \text { and } k_{M}^{C}(L S)=\bar{k}_{A}+\frac{2}{3} \varepsilon \theta .
\end{aligned}
$$


Whether the harmonized common tax rate is positive or negative crucially depends on the sign of $\theta$, as seen from (58). This is because whether the total capital endowment of the member countries (i.e., $\left.\bar{k}_{L}+\bar{k}_{S}=2 \bar{k}_{A}\right)$ is greater or smaller than their capital demands (i.e., $k_{L}^{C}(L S)+k_{S}^{C}(L S)=2 \bar{k}_{A}+(\varepsilon \theta) / 3$ ) depends on whether country $M$ is richer (i.e., $\theta>0$ ) or poorer (i.e., $\theta<0$ ). If $\theta \in[-1,0$ ), the total capital endowment of the union exceeds its total demand, and the union as a whole exports capital to the outside country $M$. In this case, the union is willing to choose a negative harmonized tax rate (i.e., subsidy) in order to raise their remuneration on capital, and vice versa if $\theta \in(0,1]$. Note, however, that countries $L$ and $S$ in the union are, respectively, a capital exporter and importer regardless of the value of $\theta$, which can be verified from (60) that $\bar{k}_{L}-k_{L}^{C}(L S)=\varepsilon(6-\theta) / 6>0$ and $\bar{k}_{S}-k_{S}^{C}(L S)=-\varepsilon(6+\theta) / 6<0$.

The tax union as a whole may be an importer or exporter, while the outside country $M$ becomes a capital importer with taxation if $\theta \in[-1,0)$ (i.e., $\tau_{M}^{C}(L S)>0$ due to (58)), or an exporter with subsidy if $\theta \in(0,1]$ (i.e., $\tau_{M}^{C}(L S)<0$ due to $(58)$ ), while it sets $\tau_{M}^{C}(L S)=0$ if $\theta=0$. By the same token, it can be seen from (58) that the sign of the harmonized tax rate is inversely related to the sign of the tax chosen by the country $M$.

The utility levels of the member countries, denoted by $u_{i}^{C}(L S), i=L, S$, are as follows:

$$
\begin{aligned}
& u_{L}^{C}(L S)=\left(a-\bar{k}_{A}\right) \bar{k}_{A}+\left(a-2 \bar{k}_{A}\right) \varepsilon-\frac{1}{36} \varepsilon^{2} \theta(36-5 \theta), \\
& u_{S}^{C}(L S)=\left(a-\bar{k}_{A}\right) \bar{k}_{A}-\left(a-2 \bar{k}_{A}\right) \varepsilon+\frac{1}{36} \varepsilon^{2} \theta(36+5 \theta) .
\end{aligned}
$$

By utilizing (9), (11), (61), and (62), we obtain the participation constraints for the two countries as follows:

$$
\begin{aligned}
& u_{L}^{C}(L S)-u_{L}^{N}=\frac{1}{324} \varepsilon^{2}\left(13 \theta^{2}-132 \theta+36\right) \geq 0 \text { for } \theta \in\left[-1, \frac{66-36 \sqrt{3}}{13}\right] \\
& u_{S}^{C}(L S)-u_{S}^{N}=\frac{1}{324} \varepsilon^{2}\left(13 \theta^{2}+132 \theta+36\right) \geq 0 \text { for } \theta \in\left[\frac{-66+36 \sqrt{3}}{13}, 1\right]
\end{aligned}
$$

the overlapping range for both gives the following range of harmonized tax rates:

$$
\theta \in\left[\frac{-66+36 \sqrt{3}}{13}, \frac{66-36 \sqrt{3}}{13}\right]
$$

The best-deviation tax rates of countries $L$ and $S$, denoted by $\tau_{i}^{D}(L S), i=L, S$, are chosen by maximizing $u_{i}$ given that the other countries follow the tax rates given by (58). Setting $\tau_{j}=\tau^{C}(L S)$ 
for $L$ and $S$ and $\tau_{M}=\tau_{M}^{C}(L S)$ in (5) yields the best-deviation tax rates of the two countries:

$$
\tau_{L}^{D}(L S)=-\frac{1}{24} \varepsilon(18-7 \theta) \text { and } \tau_{S}^{D}(L S)=\frac{1}{24} \varepsilon(18+7 \theta) .
$$

When country $L$ deviates from $\tau^{C}(L S)$ by setting $\tau_{L}^{D}(L S)$, while countries $M$ and $S$ follow their tax rates $\tau_{M}^{C}(L S)$ and $\tau^{C}(L S)$, respectively, the net return on capital, the capital demand in country $L$, and the resulting utility level are, respectively, obtained by making use of (1), (2), (58), and (66):

$$
\begin{aligned}
r_{L}^{D}(L S) & =a-2 \bar{k}_{A}+\frac{1}{8} \varepsilon(2-7 \theta), \\
k_{L}^{D}(L S) & =\bar{k}_{A}+\frac{1}{24} \varepsilon(6+7 \theta), \\
u_{L}^{D}(L S) & =\left(a-\bar{k}_{A}\right) \bar{k}_{A}+\left(a-2 \bar{k}_{A}\right) \varepsilon+\frac{1}{288} \varepsilon^{2}\left(49 \theta^{2}-252 \theta+36\right) .
\end{aligned}
$$

Similarly, if country $S$ deviates from $\tau^{C}(L S)$ by setting $\tau_{S}^{D}(L S)$, we have the following:

$$
\begin{aligned}
& r_{S}^{D}(L S)=a-2 \bar{k}_{A}-\frac{1}{8} \varepsilon(2+7 \theta), \\
& k_{S}^{D}(L S)=\bar{k}_{A}-\frac{1}{24} \varepsilon(6-7 \theta), \\
& u_{S}^{D}(L S)=\left(a-\bar{k}_{A}\right) \bar{k}_{A}-\left(a-2 \bar{k}_{A}\right) \varepsilon+\frac{1}{288} \varepsilon^{2}\left(49 \theta^{2}+252 \theta+36\right) .
\end{aligned}
$$

Using (9), (11), (25), (61), (62), (67), and (68), we obtain the following minimum discount factors of countries $L$ and $S$ in the union, respectively:

$$
\begin{aligned}
\underline{\delta}_{L}(L S) & =\frac{u_{L}^{D}(L S)-u_{L}^{C}(L S)}{u_{L}^{D}(L S)-u_{L}^{N}}=\frac{81(2+\theta)^{2}}{(6-5 \theta)(102-37 \theta)}, \\
\underline{\delta}_{S}(L S) & =\frac{u_{S}^{D}(L S)-u_{S}^{C}(L S)}{u_{S}^{D}(L S)-u_{S}^{N}}=\frac{81(2-\theta)^{2}}{(6+5 \theta)(102+37 \theta)} .
\end{aligned}
$$

As long as $\theta$ satisfies the participation constraint (65), the partial harmonization between $L$ and $S$ is sustainable, i.e., there exists a positive interval of $\theta$ such that $\underline{\delta}_{i}(L S)<1, i=L, S$, as illustrated in Fig.8). Furthermore, we can show that $\underline{\delta}_{L}(L S)$ in (69) is increasing in $\theta$, while $\underline{\delta}_{S}(L S)$ in (70) is decreasing in $\theta$, and that the loci of these minimum discount factors intersect each other when $\theta=0$; that is, $\underline{\delta}_{L}(L S)=\underline{\delta}_{S}(L S)=9 / 17$ at $\theta=0$, as drawn in Fig.8.

These observations lead to the following proposition:

Proposition 5 (i) If the large and small countries are sufficiently patient, then the partial tax harmonization between them can be sustained as a subgame perfect Nash equilibrium of the repeated tax 


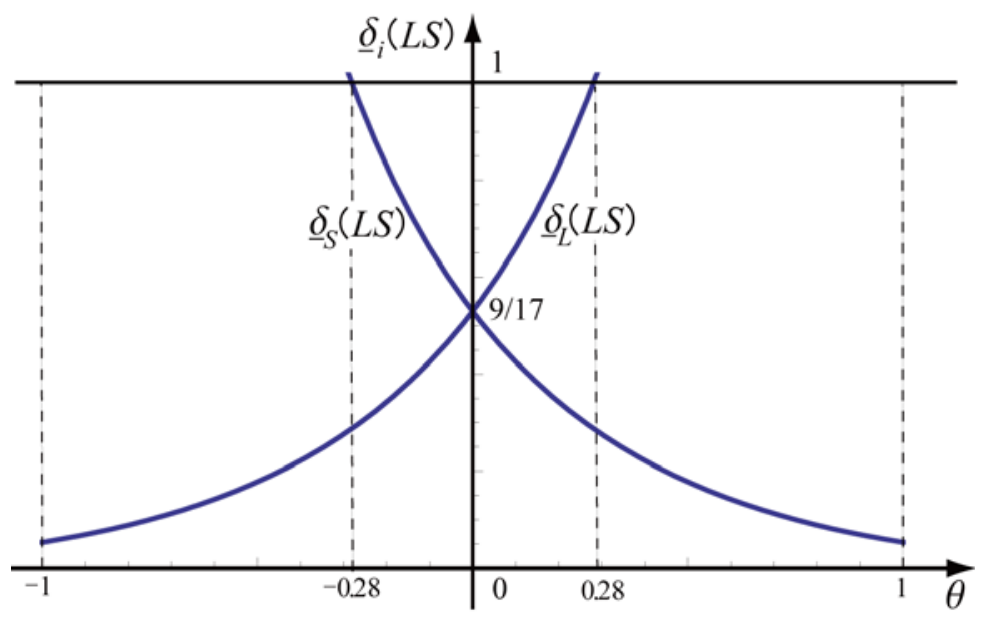

Figure 8: Loci of the minimum discount factors of countries $L$ and $S$.

competition game;

(ii) as the capital endowment of the median country becomes closer to the average capital endowment of the large and small countries, it is more likely that partial tax harmonization prevails;

(iii) when the capital endowment of the median country is equal to the average capital endowment of the large and small countries (i.e., $\theta=0$ ), it is most likely that partial tax harmonization prevails; and

(iv) the sustainability of partial tax harmonization is independent of the difference in the capital endowments of the large and small countries (measured by $2 \varepsilon$ ).

To understand the economic logic behind Proposition 5 (see also Fig.8), suppose that $\theta>0$ and $\theta$ is increased. In this case, the tax union imports capital from country $M$. As seen from (58), the union members agree to choose a positive harmonized tax rate in order to reduce their capital payments. Due to the increased total supply of capital associated with a larger $\theta,{ }^{C}(L S)$ tends to decline, which in turn induces the capital-exporting country $M$ to lower $\tau_{M}^{C}(L S)$, while the union will raise $\tau^{C}(L S)$ due to the strategic complementarity of the taxes. According to $(59), r^{C}(L S)$ unambiguously falls with $\theta$, thereby boosting the demand for capital. The remuneration on capital ${ }_{r}^{C}(L S)\left[\bar{k}_{i}-k_{i}^{C}(L S)\right]$ decreases for country $L$ (i.e., the exporter), while it is ambiguous for country $S$ (i.e., the importer). Although the outputs of both countries, $f\left(k_{i}^{C}(L S)\right), i=L, S$, unambiguously increase, the overall effects on $u_{i}^{C}(M S) \equiv f\left(k_{i}^{C}(L S)\right)+r^{C}(L S)\left[\bar{k}_{i}-k_{i}^{C}(L S)\right], i=L, S$, appear to be 
ambiguous. Nevertheless, it can be shown by differentiating (63) and (64) with respect to $\theta$ that

$$
\begin{aligned}
& \frac{\partial u_{L}^{C}(L S)}{\partial \theta}=-\frac{1}{18} \varepsilon^{2}(18-5 \theta)<0, \\
& \frac{\partial u_{S}^{C}(L S)}{\partial \theta}=\frac{1}{18} \varepsilon^{2}(18+5 \theta)>0 .
\end{aligned}
$$

Moreover, we find that

$$
\begin{aligned}
& \frac{\partial u_{L}^{C}(L S)}{\partial \theta}-\frac{\partial u_{L}^{N}}{\partial \theta}=\frac{1}{162} \varepsilon^{2}(13 \theta-66)<0, \\
& \frac{\partial u_{S}^{C}(L S)}{\partial \theta}-\frac{\partial u_{S}^{N}}{\partial \theta}=\frac{1}{162} \varepsilon^{2}(13 \theta+66)>0 .
\end{aligned}
$$

These results together imply that the minimum discount factor of country $L$ in (69) (country $S$ in (70)) rises (falls) with $\theta$, as illustrated in Fig.8. When $\theta<0$, the results stated above are reversed.

In short, when the tax union is an importer (i.e., $\theta>0$ ), the capital exporting country $L$ is frustrated by the positive harmonized tax rate. As $\theta$ becomes larger, the union will import more capital from country $M$, and hence country $L$ becomes more frustrated, which in turn enhances the incentive of country $L$ to deviate. Conversely, when the tax union is an exporter (i.e., $\theta<0$ ), the capital-importing country $S$ is more frustrated with a lower $\theta$, and hence its incentive to deviate is strengthened as $\theta$ becomes smaller. Therefore, we may conclude that the likelihood of sustainability for the tax harmonization consisting of countries $L$ and $S$ relies heavily on the net exporting position of the capital of the member countries.

\section{Who Gains from Partial Tax Harmonization?}

In this section, we compare the welfare levels of the countries at the fully noncooperative Nash equilibrium and the subgroup Nash equilibria associated with the three types of partial tax harmonization that we have considered so far. Under the partial union consisting of countries $L$ and $M$, it follows from the participation constraints (35) and (36) that the welfare levels of these member countries are unambiguously improved, whereas by utilizing (11), (31), and (32), it is straightforward to show that

$$
u_{S}^{N}-u_{S}^{C}(L M)=\frac{7}{162} \varepsilon^{2}(3+\theta)^{2}>0 .
$$

That is, the residents of country $S$ that is outside the union are always worse off compared to those in the Nash equilibrium. The reason for this is quite straightforward. The capital-exporting tax 
union tends to lower $\tau^{C}(L M)$ in order to increase its remuneration on capital, whereas the capitalimporting country $S$ is willing to raise $\tau_{S}^{C}(L M)$ in order to reduce its capital payment. Consequently, ${ }^{C}(L M)$ has to be smaller than $r^{N}$, which is implied by (5). Since the union has a bigger share in determining the average tax rate $\bar{\tau}$, it can exert market power on the world capital market. As a result, the capital-exporting union can manipulate the net return in its favor, resulting in a higher net return on capital, which ends up harming the welfare of the outside country.

Similarly, under the partial harmonization between countries $M$ and $S$, it follows from (9), (46), and (47) that

$$
u_{L}^{N}-u_{L}^{C}(M S)=\frac{7}{162} \varepsilon^{2}(3-\theta)^{2}>0,
$$

which implies that country $L$ is always harmed, while countries $M$ and $S$ are always better off due to their participation constraints. Since the tax union, which is a capital importer, exerts market power on the world capital market, it can lower the net return on capital to reduce its capital payment. The decreased net return benefits the capital-importing union, whereas it harms the outside country $L$ that is a capital exporter.

Finally, it follows from (10), (59), and (60) that

$$
u_{M}^{N}-u_{M}^{C}(L S)=\frac{14}{81} \varepsilon^{2} \theta^{2} \geq 0
$$

Since the tax union may be a capital exporter or importer, it can lower or raise the net return by manipulating $\tau^{C}(L S)$ in its favor. In any case, the union can manipulate the net return in its favor, which ends up harming the welfare of the outside country $M$ except for $\theta=0$.

These results significantly differ from Konrad and Schjelderup (1999), Rasmussen (2001), Kachelein (2004), Sugahara et al. (2009), Bucovetsky (2009), and Vrijburg (2009) that have shown that partial tax harmonization can improve not only the welfare of the union but also that of the outside countries. Their results are essentially the same as that in the asymmetric two-country model of Wilson (1991), which demonstrates that a small country is always better off compared to a large country. This is because "a large country", which is usually a capital exporter, charges a higher tax rate than average, which in turn reduces the net return and thus increases the tax base of "the small country", harming the capital exporter. In their models, the tax union of cooperating countries can be considered as the "large country", and the outside country as the "small country"; hence, the welfare gain from tax harmonization of the member countries would be smaller than that of the 
outside country. In contrast, since in our heterogenous capital endowment model, the net exporting positions of the capital of the tax union and the outside country are completely opposed, they have opposite incentives to manipulate the capital prices, i.e., the terms of trade effect, in their favor.

\section{Concluding Remarks}

In this paper, we have examined how capital tax harmonization is sustained in a repeated interactions model of tax competition. We have found the following noteworthy results. First, the sustainability of tax harmonization in a subset of heterogenous countries crucially depends on the capital endowment of the median country relative to the large (or small) country (which is measured by $\theta$ ). More precisely, the closer the capital endowment of the median country to the average capital endowment of the large and small countries (i.e., $\theta \rightarrow 0$ ), the less likely are both the full and partial harmonizations involving the median country to be sustained, and the more likely is the partial tax harmonization excluding the median country to be sustained. When the median country is included in the tax union, the median country always has a stronger incentive to deviate compared to the large and small countries. The reason for this is that when the median country is in the tax union, it always has to make income transfers to its partner owing to the common tax rate, while when it is not in the union, the closer its capital endowment to the average capital amount, the less the amount of trading and consequently the less the amount of income transfers between the member countries within the union. In short, the size of income transfers within the tax union plays a key role in determining the sustainability of tax harmonization.

Second, as seen from Fig.9, which illustrates the minimum discount factors of the respective countries under all possible partial tax unions, there are subsets (intervals) of $\theta$ having a strictly positive Lebesgue measure wherein partial tax harmonization is impossible. In contrast, full tax harmonization can be sustained almost everywhere in the whole interval of $\theta$ (i.e., $[-1,1]$ ) except for a single point $\theta=0$, which has zero Lebesgue measure. This observation reveals not only that the location of the capital endowment of the median country plays a key role in the successful implementation of any partial tax harmonization but also that partial harmonization is less likely to be sustained as compared to full harmonization.

Third, the likelihood of partial harmonization between any union members depends only on $\theta$ and not on $\varepsilon$. In other words, the scale effect measured by $\varepsilon$ does not affect the likelihood of partial harmonization. This strong feature would stem from the property of linear utility functions, because 


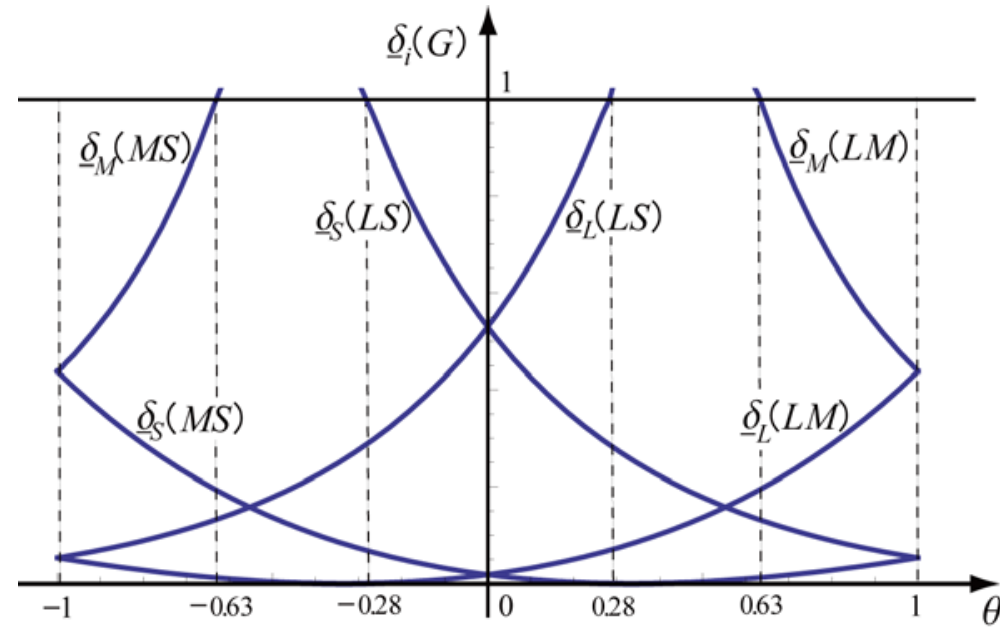

Figure 9: Minimum discount factors of the respective coutries under all partial harmonizations.

larger values of $\varepsilon$ increase the utility levels of the respective countries, but do not affect their minimum discount factors due to the assumption of linear utility. Nevertheless, it remains to be seen as to how under more general nonlinear utility functions, the changes in $\varepsilon$ affect the likelihood of partial tax harmonization.

Fourth, the results of this paper may help to explain why the introduction of ECAs is sometimes opposed by outside countries. According to our results, the tax union and the outside country always have diverse interests such that the tax union always gains from partial harmonization, while the outside country always losses, because of their opposed net exporting position of capital and because the partial tax union manipulates its common tax rate in its favor. Hence, the introduction of ECAs is not Pareto improving unless the excluded countries are compensated for their losses. Our theoretical result suggests that for the formation of ECAs on selected issues, the losers outside the ECA need to be compensated by side payments. Although the Treaty of Nice does not require any mechanism of monetary compensation, it would be necessary to design institutions to allow for compensatory transfers to the excluded countries that make it easy for a (qualified) majority of member countries in the EU to agree to form an ECA.

Finally, the results obtained in this paper critically rely on the restrictive structure of the present model; e.g., a linear utility function and a quadratic production function in a three-country setting. To ascertain the robustness of our results, we have to conduct the same analysis under more general functions and/or include more than three countries. To make the analysis under such a generalized model tractable, we need to resort to a numerical analysis. In particular, it is quite interesting to check the robustness of our results in a model featuring an arbitrary number of heterogenous 
countries.

\section{Appendix}

In order to draw the graphs of $\underline{\delta}_{i}, i=L, M, S$, under full tax harmonization, we first express $\underline{\delta}_{i}$ as a function of $\tau^{C}$; i.e., $\underline{\delta}_{i}\left(\tau^{C}\right)$. When $\theta \in(0,1]$, substituting the lower- and upper-bound values of $\tau^{C}$ given by (18) (i.e., $\tau_{\min }^{C} \equiv-\varepsilon(3+\theta) / 27$ and $\left.\tau_{\max }^{C} \equiv 2 \varepsilon \theta / 27\right)$ into (26), (27), and (28) yields

$$
\begin{array}{ll}
\underline{\delta}_{L}\left(\tau_{\min }^{C}\right)=\frac{(12-5 \theta)^{2}}{(6-\theta)(78-25 \theta)}, & \underline{\delta}_{L}\left(\tau_{\max }^{C}\right)=\frac{(27-7 \theta)^{2}}{(9-5 \theta)(153-53 \theta)} \\
\underline{\delta}_{M}\left(\tau_{\min }^{C}\right)=\frac{(3-17 \theta)^{2}}{(3+7 \theta)(3+103 \theta)}, & \underline{\delta}_{M}\left(\tau_{\max }^{C}\right)=1 \\
\underline{\delta}_{S}\left(\tau_{\min }^{C}\right)=1, & \underline{\delta}_{S}\left(\tau_{\max }^{C}\right)=\frac{(27+7 \theta)^{2}}{(9+5 \theta)(153+53 \theta)}
\end{array}
$$

Similarly, when $\theta \in[-1,0)$, the values of $\underline{\delta}_{i}\left(\tau^{C}\right), i=L, M, S$, are given by

$$
\begin{array}{ll}
\underline{\delta}_{L}\left(\tau_{\min }^{C}\right)=\frac{(27-7 \theta)^{2}}{(9-5 \theta)(153-53 \theta)}, & \underline{\delta}_{L}\left(\tau_{\max }^{C}\right)=1, \\
\underline{\delta}_{M}\left(\tau_{\min }^{C}\right)=1, & \underline{\delta}_{M}\left(\tau_{\max }^{C}\right)=\frac{(3+17 \theta)^{2}}{(3-7 \theta)(3-103 \theta)}, \\
\underline{\delta}_{S}\left(\tau_{\min }^{C}\right)=\frac{(27+7 \theta)^{2}}{(9+5 \theta)(153+53 \theta)}, & \underline{\delta}_{S}\left(\tau_{\max }^{C}\right)=\frac{(12+5 \theta)^{2}}{(6+\theta)(78+25 \theta)},
\end{array}
$$

where $\tau_{\min }^{C} \equiv 2 \varepsilon \theta / 27$ and $\tau_{\max }^{C} \equiv \varepsilon(3-\theta) / 27$ stand for the lower- and upper-bound values of $\tau^{C}$, respectively, and $\underline{\delta}_{L}(0)=\underline{\delta}_{M}(0)=\underline{\delta}_{S}(0)=9 / 17$.

Differentiating $\underline{\delta}_{i}\left(\tau^{C}\right), i=L, M, S$, with respect to $\tau^{C}$, respectively, yields

$$
\begin{aligned}
\frac{\partial \underline{\delta}_{L}}{\partial \tau^{C}}= & -\frac{216 \varepsilon(3-\theta)\left[3 \tau^{C}+\varepsilon(3-\theta)\right]\left[27 \tau^{C}-11 \varepsilon(3-\theta)\right]}{\left[9 \tau^{C}-\varepsilon(3-\theta)\right]^{2}\left[9 \tau^{C}-17 \varepsilon(3-\theta)\right]^{2}}>0, \\
\frac{\partial \underline{\delta}_{M}}{\partial \tau^{C}}= & -\frac{432 \varepsilon \theta\left(3 \tau^{C}+2 \varepsilon \theta\right)\left(27 \tau^{C}-22 \varepsilon \theta\right)}{\left(9 \tau^{C}-2 \varepsilon \theta\right)^{2}\left(9 \tau^{C}-34 \varepsilon \theta\right)^{2}} \\
\frac{\partial \underline{\delta}_{S}}{\partial \tau^{C}} & =\frac{216 \varepsilon(3+\theta)\left[3 \tau^{C}-\varepsilon(3+\theta)\right]\left[27 \tau^{C}+11 \varepsilon(3+\theta)\right]}{\left[9 \tau^{C}+\varepsilon(3+\theta)\right]^{2}\left[9 \tau^{C}+17 \varepsilon(3+\theta)\right]^{2}}<0 .
\end{aligned}
$$

(A1) and (A3) imply that $\underline{\delta}_{L}\left(\underline{\delta}_{S}\right)$ is increasing (decreasing) in $\tau^{C}$ in (18). On other hand, (A2) implies that $\underline{\delta}_{M}$ is increasing (decreasing) in $\tau^{C}$ if $\theta>3 / 17(\theta<-3 / 17)$ within the tax range given by (18), while it is not monotonic in $\tau^{C}$ when $\theta \in[-3 / 17,3 / 17]$ since $\underline{\delta}_{M}$ reaches a local minimum point for $\tau^{C}$ within the tax range given by (18). Moreover, we can prove that $\partial \underline{\delta}_{M} / \partial \tau^{C}>0$ if $\theta \in(0$, 1] and $\tau^{C}>0$, while $\partial \underline{\delta}_{M} / \partial \tau^{C}<0$ if $\theta \in[-1,0)$ and $\tau^{C}<0$. Furthermore, evaluation at the 


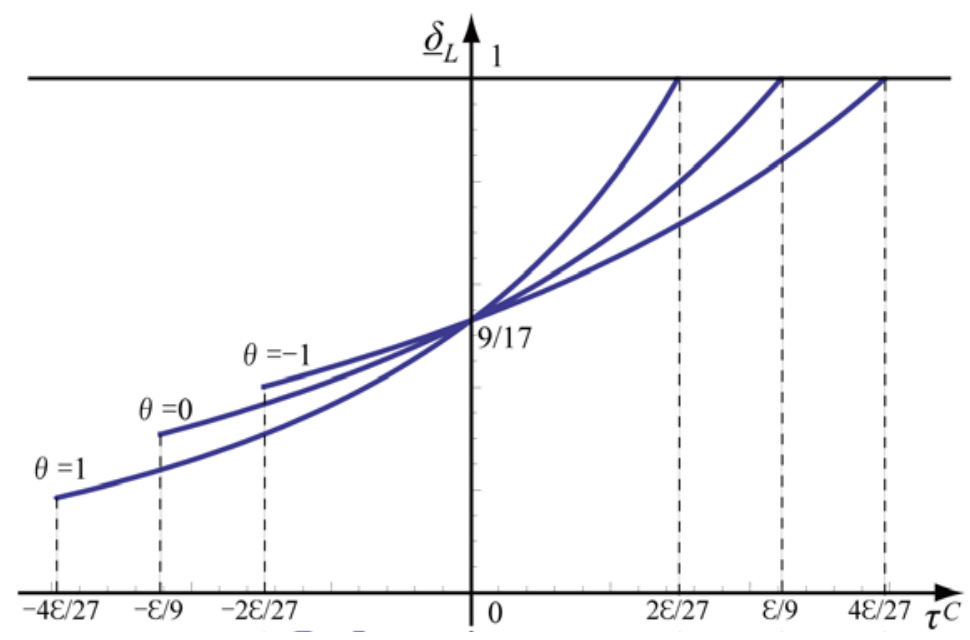

Figure 10: Loci of the minimum discount factors of country $L$ if $\theta=-1,0$, and 1 .

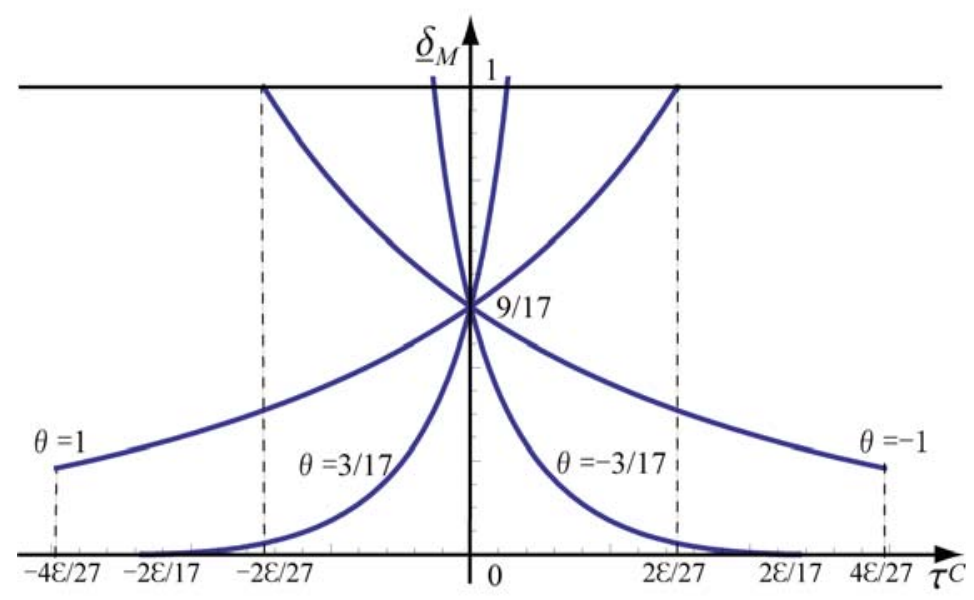

Figure 11: Loci of the minimum discount factors of country $M$ if $\theta=-1,-3 / 17,3 / 17$, and 1 .

intersection point yields the following:

$$
\begin{aligned}
\left.\frac{\partial \underline{\delta}_{L}}{\partial \tau^{C}}\right|_{\tau^{C}=0} & \leq\left.\frac{\partial \underline{\delta}_{M}}{\partial \tau^{C}}\right|_{\tau^{C}=0} \quad \text { for } \theta \in(0,1] \\
\left|\frac{\partial \underline{\delta}_{M}}{\partial \tau^{C}}\right|_{\tau^{C}=0} \mid & \geq\left|\frac{\partial \underline{\delta}_{S}}{\partial \tau^{C}}\right|_{\tau^{C}=0} \mid \text { for } \theta \in[-1,0),
\end{aligned}
$$

where $\underline{\delta}_{L}=\underline{\delta}_{M}$ if $\theta=1$, while $\underline{\delta}_{M}=\underline{\delta}_{S}$ if $\theta=-1$. Figs.10, 11, and 12, respectively, illustrate the loci of the minimum discount factors of country $i=L, M, S, \underline{\delta}_{i}$.

Differentiating the minimum discount factors $\underline{\delta}_{i}, i=L, M, S$, with respect to $\theta$ yields the 


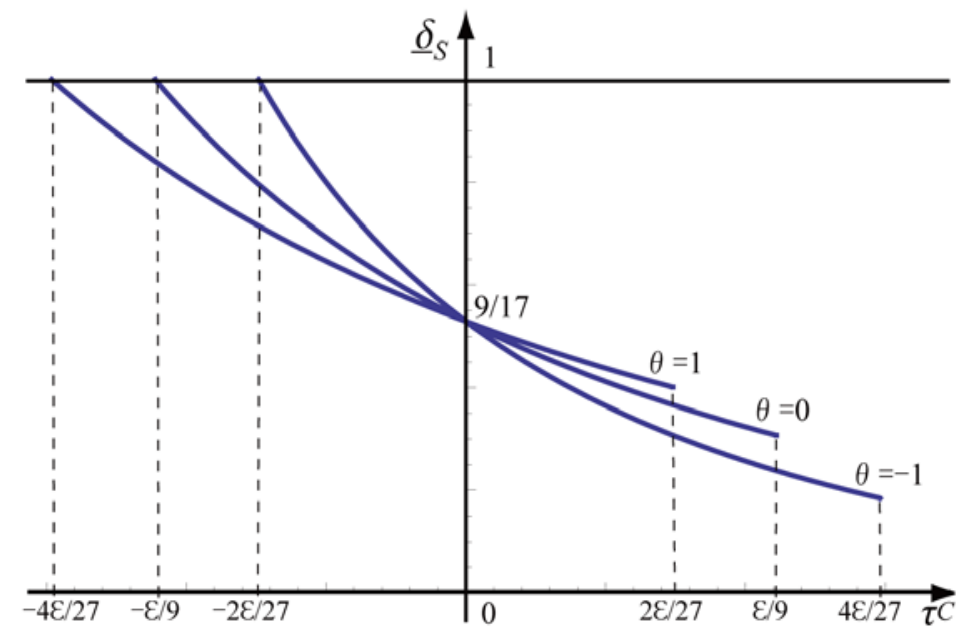

Figure 12: Loci of the minimum discount factors of country $S$ if $\theta=-1,0$, and 1 .

following:

$$
\begin{aligned}
\frac{\partial \underline{\delta}_{L}}{\partial \theta} & =-\frac{216 \varepsilon\left[3 \tau^{C}+\varepsilon(3-\theta)\right]\left[27 \tau^{C}-11 \varepsilon(3-\theta)\right] \tau^{C}}{\left[9 \tau^{C}-\varepsilon(3-\theta)\right]^{2}\left[9 \tau^{C}-17 \varepsilon(3-\theta)\right]^{2}} \gtreqless 0 \text { iff } \tau^{C} \gtreqless 0, \\
\frac{\partial \underline{\delta}_{M}}{\partial \theta} & =\frac{432 \varepsilon\left(3 \tau^{C}+2 \varepsilon \theta\right)\left(27 \tau^{C}-22 \varepsilon \theta\right) \tau^{C}}{\left(9 \tau^{C}-2 \varepsilon \theta\right)^{2}\left(9 \tau^{C}-34 \varepsilon \theta\right)^{2}}, \\
\frac{\partial \underline{\delta}_{S}}{\partial \theta} & =-\frac{216 \varepsilon\left[3 \tau^{C}-\varepsilon(3+\theta)\right]\left[27 \tau^{C}+11 \varepsilon(3+\theta)\right] \tau^{C}}{\left[9 \tau^{C}+\varepsilon(3+\theta)\right]^{2}\left[9 \tau^{C}+17 \varepsilon(3+\theta)\right]^{2}} \gtreqless 0 \text { iff } \tau^{C} \gtreqless 0 .
\end{aligned}
$$

Similarly, differentiating $\underline{\delta}_{i}, i=L, M, S$, with respect to $\varepsilon$ yields the following:

$$
\begin{aligned}
\frac{\partial \underline{\delta}_{L}}{\partial \varepsilon} & =\frac{216(3-\theta)\left[3 \tau^{C}+\varepsilon(3-\theta)\right]\left[27 \tau^{C}-11 \varepsilon(3-\theta)\right] \tau^{C}}{\left[9 \tau^{C}-\varepsilon(3-\theta)\right]^{2}\left[9 \tau^{C}-17 \varepsilon(3-\theta)\right]^{2}} \lesseqgtr 0 \text { iff } \tau^{C} \gtreqless 0, \\
\frac{\partial \underline{\delta}_{M}}{\partial \varepsilon} & =\frac{432 \theta\left(3 \tau^{C}+2 \varepsilon \theta\right)\left(27 \tau^{C}-22 \varepsilon \theta\right) \tau^{C}}{\left(9 \tau^{C}-2 \varepsilon \theta\right)^{2}\left(9 \tau^{C}-34 \varepsilon \theta\right)^{2}}, \\
\frac{\partial \underline{\delta}_{S}}{\partial \varepsilon} & =-\frac{216(3+\theta)\left[3 \tau^{C}-\varepsilon(3+\theta)\right]\left[27 \tau^{C}+11 \varepsilon(3+\theta)\right] \tau^{C}}{\left[9 \tau^{C}+\varepsilon(3+\theta)\right]^{2}\left[9 \tau^{C}+17 \varepsilon(3+\theta)\right]^{2}} \gtreqless 0 \text { iff } \tau^{C} \gtreqless 0,
\end{aligned}
$$

It can be readily seen that when $\tau^{C}>(<) 0$, the threshold value of the discount factor, $\delta^{*}$, is always equal to $\underline{\delta}_{M}$ if $\theta \in(0,1](\theta \in[-1,0))$. Define $\Phi_{M L}(\theta) \equiv \underline{\delta}_{M}-\underline{\delta}_{L}$ and $\Phi_{M S}(\theta) \equiv \underline{\delta}_{M}-\underline{\delta}_{S}$ with $\Phi_{M L}(1)=\Phi_{M S}(-1)=0$. If $\theta \in(0,1)$, then from (A6) and (A7) we get that $\partial \Phi_{M L}(\theta) / \partial \theta<0$ for $\tau^{C}>0$. Similarly, if $\theta \in(-1,0)$, it follows from (A7) and (A8) that $\partial \Phi_{M S}(\theta) / \partial \theta>0$ for $\tau^{C}<0$. These results, together with (A4) and (A5), reveal that if $\theta \in(0,1](\theta \in[-1,0))$, then $\underline{\delta}_{M}$ is greater than $\underline{\delta}_{L}\left(\underline{\delta}_{S}\right)$ for $\tau^{C}>(<) 0$. 


\section{References}

Bucovetsky, S. (1991) Asymmetric tax competition, Journal of Urban Economics 30, 167-181.

Bucovetsky, S. (2009) An index of capital tax competition, International Tax and Public Finance 16, 727-752.

Burbidge, J., J. de Pater, G. Myers, and A. Sengupta (1997) A coalition-formation approach to equilibrium federations and trading blocs, American Economic Review 87, 940-956.

Cardarelli, R., E. Taugourdeau, and J-P. Vidal (2002) A repeated interactions model of tax competition, Journal of Public Economic Theory 4, 19-38.

Catenaro, M. and J.-P. Vidal (2006) Implicit tax coordination under repeated policy interactions, Recherches Economiques de Louvain 72, 1-17.

Itaya, J., M. Okamura, and C. Yamaguchi (2008) Are regional asymmetries detrimental to tax coordination in a repeated game setting?, Journal of Public Economics 92, 2403-2411.

Kächelein, H (2004) Capital Tax Comeptition and Partial Cooperation: Welfare Enhancing or not?, BERG Working Paper Series on Government and Growth \#51, Bamberg University.

Konrad, K. A., and G. Schjelderup (1999) Fortress building in global tax competition, Journal of Urban Economics 46, 156-167.

Peralta, S., and T. van Ypersele (2006) Coordination of capital taxation among asymmetric countries, Regional Science and Urban Economics 36, 708-726.

Rasmussen, S. (2001) Partial vs. global coordination of capital income tax policies, Working Paper No. 2001-3, University of Aarhus.

Sugahara, K., M. Kunizaki, and K. Oshima (2009) Partial tax coordination in multilateral asymmetric tax competition, Discussion Paper Series \#2009-01, Kyoto Sangyo University.

Vrijburg, H. (2009) Partial Harmonization in Corporate Taxes, mimo.

Wilson, J. D. (1991) Tax competition with interregional differences in factor endowments, Regional Science and Urban Economics 21, 423-451. 